\title{
How MJO Teleconnections and ENSO Interference Impacts U.S. Precipitation
}

\author{
Marybeth C. Arcodia, Ben P. Kirtman, and Leo S. P. Siqueira \\ Rosenstiel School of Marine and Atmospheric Science, University of Miami, Miami, Florida
}

(Manuscript received 18 June 2019, in final form 26 February 2020)

\begin{abstract}
A composite analysis reveals how the Madden-Julian oscillation (MJO) impacts North American rainfall through perturbations in both the upper-tropospheric flow and regional low-level moisture availability. Upper-level divergence associated with the MJO tropical convection drives a quasi-stationary Rossby wave response to the midlatitudes. This forces a midlatitude upper-level dipolar geopotential height anomaly that is accompanied by a westward retraction of the jet stream and reduced rainfall over the central-eastern North Pacific. A reverse effect is found as the MJO propagates eastward across the Maritime Continent. These large differences in the extratropical upper-level flow, combined with anomalies in the regional supply of water vapor, have a profound impact on southeastern U.S. rainfall. The low-frequency variability, including that associated with ENSO, can modify the seasonal background flow (e.g., El Niño and La Niña basic states) affecting the distribution, strength, and propagation of the intraseasonal oscillation and the extratropical teleconnection patterns. The combined effects of the ENSO and the MJO signals result in both spatial and temporal patterns of interference and modulation of North American rainfall. The results from this study show that during a particular phase of an active MJO, the extratropical response can considerably enhance or mask the interannual ENSO signal in the United States, potentially resulting in anomalies of the opposite sign than that expected during a specific ENSO phase. Analyses of specific MJO events during an El Niño or La Niña episode reveal significant contributions to extreme events via constructive and destructive interference of the MJO and ENSO signals.
\end{abstract}

\section{Introduction}

The subseasonal time scale of approximately 2 weeks to 2 months bridges the gap between weather and climate. Consequential phenomena such as temperature extremes, flooding and drought events, and other weather-related hazards are all encapsulated by the subseasonal range, yet this time scale is considered to be a "desert of predictability" (Vitart et al. 2017).

The dominant mode of subseasonal tropical variability is the 40-50-day oscillation commonly referred to as the Madden-Julian oscillation (MJO). The MJO is an eastward-propagating coupling between a tropospheric circulation pattern and condensational heating from deep convection in the tropical Indo-Pacific (Madden and Julian 1971, 1972; Zhang 2005). The divergent upper-level flow associated with the tropical coupling pattern forces barotropic Rossby wave trains that emanate from the tropics to the extratropics (Hoskins and Karoly 1981; Sardeshmukh and Hoskins 1988). We hereafter refer

Corresponding author: Marybeth C. Arcodia, marcodia@rsmas. miami.edu to an "MJO forcing" as the tropical heating anomalies associated with the active phase of the MJO which cause rising motion and result in a teleconnection response in the region of subtropical descent. This study focuses primarily on responses seen in the Northern Hemisphere midlatitudes.

The mean state of the atmosphere and the ocean modulate the persistence, location, strength, etc., of the extratropical signal from a tropical forcing (Stan et al. 2017). The MJO propagates eastward along the tropical Indian and western Pacific Oceans and dominates subseasonal variability (Zhang 2005). El Niño-Southern Oscillation (ENSO) dominates the Pacific region on interannual time scales, but is a spatially stationary phenomenon. ENSO can greatly affect the background state of the corresponding teleconnection patterns (Pohl and Matthews 2007). Feedbacks between the MJO and ENSO have been shown, which in turn can affect the precipitation associated with each climate mode (e.g., Hoell et al. 2014).

Tropical convection associated with both ENSO and the MJO has been shown to have effects on U.S. rainfall (Riddle et al. 2013; Stan et al. 2017). Rainfall probabilities 
and extreme precipitation events tend to occur more often in certain regions of the United States during particular active phases of the MJO than inactive MJO periods (Becker et al. 2011; Jones and Carvalho 2012). Roundy et al. (2010) and Moon et al. (2011) further examined changes in the MJO-related teleconnections during different ENSO basic states. Overall, these studies demonstrate that the extratropical response to the MJO is enhanced when the MJO tropical convection is in phase with heating and convection due to ENSO. Combining the effects of ENSO and the MJO can potentially lead to improved predictive skill out to 4 weeks (Riddle et al. 2013; Johnson et al. 2014). However, there are still gaps in the knowledge of the spatial and temporal characteristics of MJO teleconnections and the role of the ENSO-modulated background state. It follows that the research areas of both how the MJO's teleconnection signals are modulated by the mean state, particularly ENSO, and how the corresponding teleconnection signals from both oscillations interfere and affect North American weather and climate variability still have many unanswered questions.

The focus of this work is to investigate the mechanisms behind the midlatitude teleconnections associated with the active phase of the MJO and analyze constructive and destructive interference between the MJO and ENSO rainfall teleconnections in North America. The first part of the study analyzes the consistency between anomalies in the upper-level atmospheric flow, in terms of 200-mb geopotential height, divergence, and winds, moisture flux convergence, and lower-level 850-mb moisture transport, as important factors conducive to the observed precipitation anomalies (note that $1 \mathrm{mb}=1 \mathrm{hPa}$ ). The second part examines how the signals carried by the quasi-stationary Rossby waves forced by the deep convection associated with the MJO in a specific location, combined with the modulation of the background state by ENSO, affect the rainfall teleconnection signal. The combined influence of ENSO and the MJO can lead to both extreme precipitation and drought events in regions of the United States.

\section{Methodology}

In this study, the subseasonal MJO signal is isolated from lower- and higher-frequency variability. The data used were from the National Centers for Environmental Prediction-National Center for Atmospheric Research (NCEP-NCAR) reanalysis project (Kalnay et al. 1996) from 1979 to 2017 at $2.5^{\circ}$ horizontal resolution for all variables except precipitation. The Climate Prediction Center (CPC) Unified Gauge-Based Analysis of Daily Precipitation over the CONUS dataset (Xie et al. 2007) was used for precipitation and was provided by the NOAA/OAR/ESRL PSD, Boulder, Colorado, from their website at https://www.esrl.noaa.gov/psd/. The data are $0.25^{\circ}$ resolution for 1979-2017. The NCEPNCAR reanalysis precipitation data are used for the first part of the results to diagnose the mechanism for the teleconnection and the CPC precipitation data are used for analyzing the MJO signal interference with ENSO.

We define an MJO index according to the commonly accepted method of Wheeler and Hendon (2004, hereafter WH04). An EOF analysis is used to determine active MJO days based on the MJO index, which classifies days into one of eight phases based on the longitude of deep tropical convection. We removed the seasonal cycle by subtracting the daily time mean from 1979 to 2017 for each grid point to utilize the entire time series, which differs slightly from the WH04 method of subtracting the time mean and first three harmonics of the annual cycle from 1979 to 2001 . We have calculated the first three harmonics and removed them from the MJO index and we find that both the spatial structure and explained variance of the first two EOFs used for the MJO index are virtually indistinguishable from those without the first three harmonics removed. Only active days falling between November and April are used, since this season captures the strongest teleconnections in the Northern Hemisphere (Zhang 2005).

To remove interannual variability, including that associated with ENSO, we remove a centered 120-day running mean from each daily anomaly. For example, on day 120 of the time series, days 60 to 180 are averaged, and that average is subtracted from day 120 , and so forth. The variability that is linearly related with an ENSO index is not removed as in WH04, as the 120-day running mean essentially removes the long-term variability, including the interannual ENSO signal (Lin et al. 2008). Furthermore, WH04 use the previous 120-day running mean instead of a centered 120-day running mean employed here, because their study uses forecast data and a centered running mean would not be possible due to the lack of information from future time steps. However, the methodology used in previous studies retains some unwanted interannual variability and phase shifts the signals slightly. For this study, we use the centered 120-day running mean because it both effectively removes the long-term variability, including that associated with ENSO, and avoids the issue of a phase shift of the signal. The efficacy of this method is shown in Fig. 1, which shows the differences between the Niño-3.4 index and the index with the previous and centered 120-day running means removed.

After filtering the MJO signal, we compute the explained variance of the subseasonal variability. The numerator of 


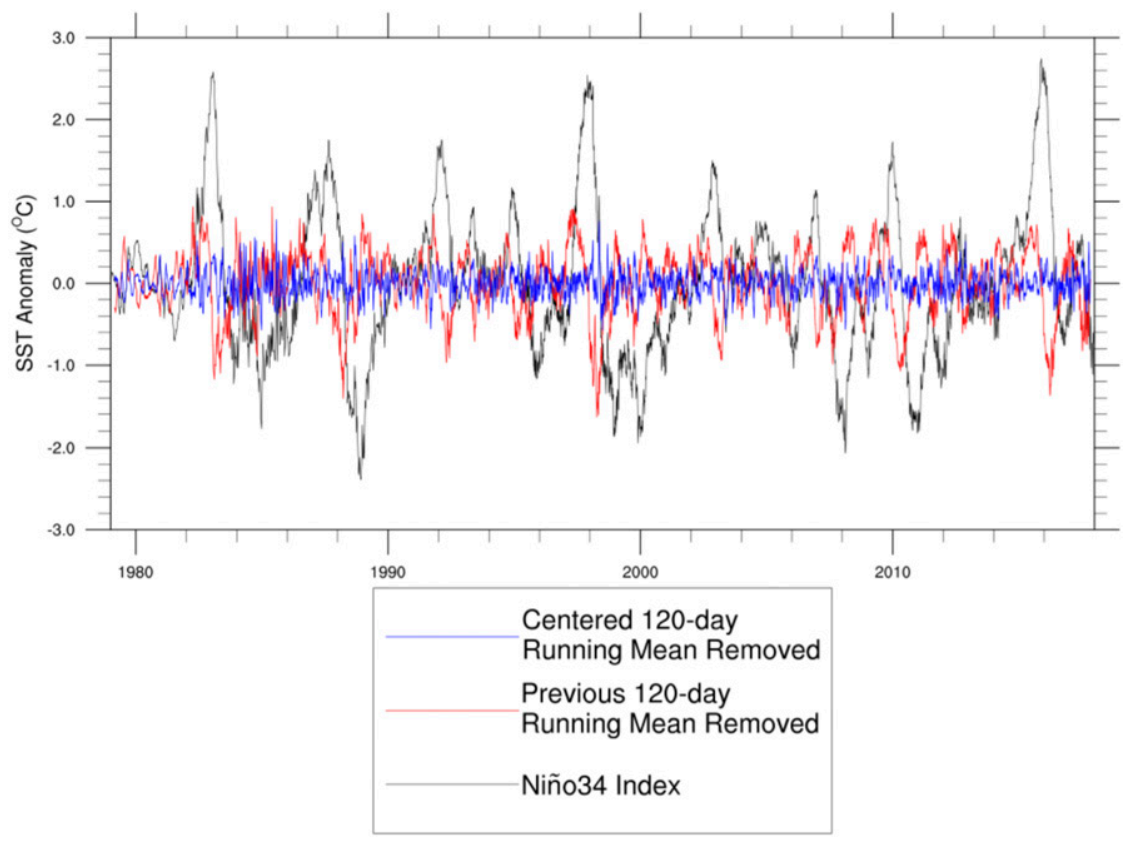

FIG. 1. Time series of the Niño-3.4 index (black) calculated using NCEP sea surface temperature daily data from 1979 to 2017 . The blue line shows the Niño-3.4 index with the centered 120-day running mean removed from the data. The red line shows the Niño-3.4 index with the previous 120-day running mean removed from the data.

the ratio is the anomaly calculated by removing the seasonal cycle and centered 120-day mean from each day and then separating these days into active or inactive days from November to April from 1979 to 2017 based on the MJO index criteria described above. The denominator is the variance of the total anomaly (only seasonal cycle removed) for all days from November to April from 1979 to 2017. The tables of explained variance show the ratio of the MJO, ENSO, and MJO + ENSO associated variability of precipitation to the total winter (November-April) variability and the total annual variability for Tables 1 and 2 , respectively. The relative importance of the subseasonal variability is further discussed in terms of the explained variance in the results section.

\section{Results: Propagation and teleconnections}

\section{a. Rainfall teleconnections}

A composite MJO life cycle of precipitation rate anomalies from NCEP-NCAR reanalysis is shown in Fig. 2. Phases 2 and 3, 4 and 5, 6 and 7, and 8 and 1 are combined for simplicity (hereafter using the format $2 \& 3,4 \& 5$, etc.). The precipitation anomalies have the seasonal cycle and interannual variability removed, as described in the methodology section. The MJO phases are defined to capture the eastward propagation of the enhanced MJO convection from the African continent to the central equatorial Pacific Ocean. The global rainfall teleconnections associated with each phase of the MJO are seen in the regions outside of the tropical band of MJO convection-predominantly the midlatitudes and eastern South America.

Analysis of precipitation data is complicated due to the small-scale features that even the highest-resolution observations and models have inadequacies in quantifying. Overland, rain gauge data are widely used because of their high spatial and temporal resolution, while reanalysis precipitation is often criticized for its relative coarser spatial resolution and heavy reliance on model parameterizations, especially parameterized convection (Zhu and Hendon 2015). For this study, the use of NCEP reanalysis precipitation is justified by the similarities between the reanalysis and rain gauge composites in the U.S. rainfall response in Fig. 3. Despite the resolution difference between the NCEP and precipitation data, the overall similarities are striking. The rainfall maintains a similar structure in both composites, although the reanalysis slightly underestimates the magnitude. The rainfall anomalies maintain the same sign regionally for each MJO phase, but the NCEP dataset shows rainfall anomalies in larger regions of the United States. The vast similarities between the rainfall structures in Fig. 3 composites justify the use of NCEP reanalysis precipitation for identifying potential drivers of spatial variation in the rainfall anomalies. Since the 
TABLE 1. Explained variance of MJO, ENSO, and MJO + ENSO to the total winter rainfall variance. The California and Gulf regions are outlined by the black boxes in the figures. Boldface numbers correspond to those variances outlined by a black box and discussed in the text.

\begin{tabular}{|c|c|c|c|c|c|c|c|c|c|}
\hline \multirow[b]{3}{*}{ Phases } & \multicolumn{3}{|c|}{ El Niño 1997/98: Fig. 11} & \multicolumn{3}{|c|}{ El Niño 2015/16: Fig. 12} & \multicolumn{3}{|c|}{ La Niña 1998-2001: Fig. 13} \\
\hline & MJO & El Niño & MJO + El Niño & MJO & El Niño & $\mathrm{MJO}+$ El Niño & MJO & La Niña & MJO + La Niña \\
\hline & \multicolumn{3}{|c|}{$\begin{array}{c}\text { California region }\left(34^{\circ}-45^{\circ} \mathrm{N},\right. \\
\left.125^{\circ}-120^{\circ} \mathrm{W}\right)\end{array}$} & \multicolumn{3}{|c|}{$\begin{array}{c}\text { California region }\left(34^{\circ}-45^{\circ} \mathrm{N} \text {, }\right. \\
\left.125^{\circ}-120^{\circ} \mathrm{W}\right)\end{array}$} & \multicolumn{3}{|c|}{$\begin{array}{c}\text { Gulf region }\left(34^{\circ}-41^{\circ} \mathrm{N},\right. \\
\left.101^{\circ}-86^{\circ} \mathrm{W}\right)\end{array}$} \\
\hline $2 \& 3$ & $4 \%$ & $3 \%$ & $11 \%$ & $2 \%$ & $2 \%$ & $1 \%$ & $<1 \%$ & $1 \%$ & $1 \%$ \\
\hline $4 \& 5$ & $43 \%$ & $8 \%$ & $18 \%$ & $2 \%$ & $2 \%$ & $5 \%$ & $1 \%$ & $1 \%$ & $2 \%$ \\
\hline $6 \& 7$ & $7 \%$ & $8 \%$ & $2 \%$ & $7 \%$ & $2 \%$ & $4 \%$ & $2 \%$ & $<\mathbf{1} \%$ & $3 \%$ \\
\hline $8 \& 1$ & $13 \%$ & $3 \%$ & $25 \%$ & $13 \%$ & $1 \%$ & $10 \%$ & $3 \%$ & $1 \%$ & $2 \%$ \\
\hline \multicolumn{10}{|c|}{ Gulf region $\left(25^{\circ}-38^{\circ} \mathrm{N}, 101^{\circ}-82^{\circ} \mathrm{W}\right)$} \\
\hline $2 \& 3$ & & $\%$ & $2 \%$ & $\%$ & & & & & \\
\hline $4 \& 5$ & & $\%$ & $4 \%$ & $\%$ & & & & & \\
\hline $6 \& 7$ & & & $3 \%$ & & & & & & \\
\hline $8 \& 1$ & & $\%$ & $1 \%$ & $\%$ & & & & & \\
\hline
\end{tabular}

reanalysis has global coverage, relationships between fields such as geopotential height and upper-level divergence and winds can be examined over the tropics and the Pacific-North American sector. For the second part of the study, the rain gauge data are used for examining the magnitude of the anomalies in more detail due to the interference of the MJO and ENSO signals in the United States.

\section{b. Atmospheric circulation and moisture transport}

The methodology described above provides an "MJO space" in which all variables filtered by this method essentially represent the signal from the aforementioned MJO forcing, at least linearly. Thus, we can examine the response of the extratropical atmosphere over the PacificNorth American sector to the intraseasonal tropical convection in Figs. 4-6. A clear 200-mb geopotential height anomaly dipole is located over the North Pacific for all phases in Fig. 4, consistent with the findings of Higgins and Mo (1997). Phases $2 \& 3$ and $4 \& 5$ in Fig. 4 show an anticyclonic anomaly poleward of a cyclonic anomaly in the Pacific sector, contributing to a decrease and westward retraction of the midlatitude jet stream toward the western Pacific. Corresponding to these changes in the upper-level flow are negative rainfall anomalies (Fig. 4) from the central-eastern North Pacific to the west coast of North America in phases $2 \& 3$ and $4 \& 5$. There are negative rainfall anomalies corresponding to these changes in the upper-level flow (Fig. 4) from the centraleastern North Pacific to the west coast of North America in phases $2 \& 3$ and $4 \& 5$. Reversed anomalies tend to occur in phases $6 \& 7$ and $8 \& 1$, showing cyclonic anomalies poleward of anticyclonic ones and enhanced precipitation, corresponding to an eastward extended

TABLE 2. Explained variance of MJO, ENSO, and MJO + ENSO to the total annual rainfall variance. The California and Gulf regions are outlined by the black boxes in the figures. Boldface numbers correspond to those variances outlined by a black box and discussed in the text.

\begin{tabular}{|c|c|c|c|c|c|c|c|c|c|}
\hline \multirow[b]{3}{*}{ Phases } & \multicolumn{3}{|c|}{ El Niño 1997/98: Fig. 11} & \multicolumn{3}{|c|}{ El Niño 2015/16: Fig. 12} & \multicolumn{3}{|c|}{ La Niña 1998-2001: Fig. 13} \\
\hline & $\mathrm{MJO}$ & El Niño & MJO + El Niño & MJO & El Niño & MJO + El Niño & $\mathrm{MJO}$ & La Niña & MJO + La Niña \\
\hline & \multicolumn{3}{|c|}{$\begin{array}{c}\text { California region }\left(34^{\circ}-45^{\circ} \mathrm{N},\right. \\
\left.125^{\circ}-120^{\circ} \mathrm{W}\right)\end{array}$} & \multicolumn{3}{|c|}{$\begin{array}{c}\text { California region }\left(34^{\circ}-45^{\circ} \mathrm{N},\right. \\
\left.125^{\circ}-120^{\circ} \mathrm{W}\right)\end{array}$} & \multicolumn{3}{|c|}{$\begin{array}{l}\text { Gulf region }\left(34^{\circ}-41^{\circ} \mathrm{N},\right. \\
\left.101^{\circ}-86^{\circ} \mathrm{W}\right)\end{array}$} \\
\hline $2 \& 3$ & $7 \%$ & $5 \%$ & $18 \%$ & $4 \%$ & $3 \%$ & $2 \%$ & $<1 \%$ & $1 \%$ & $1 \%$ \\
\hline $4 \& 5$ & $69 \%$ & $13 \%$ & $29 \%$ & $4 \%$ & $3 \%$ & $7 \%$ & $1 \%$ & $1 \%$ & $2 \%$ \\
\hline $6 \& 7$ & $13 \%$ & $14 \%$ & $3 \%$ & $11 \%$ & $2 \%$ & $6 \%$ & $2 \%$ & $<\mathbf{1} \%$ & $3 \%$ \\
\hline $8 \& 1$ & $23 \%$ & $4 \%$ & $43 \%$ & $20 \%$ & $2 \%$ & $15 \%$ & $3 \%$ & $1 \%$ & $2 \%$ \\
\hline \multicolumn{10}{|c|}{ Gulf region $\left(25^{\circ}-38^{\circ} \mathrm{N}, 101^{\circ}-82^{\circ} \mathrm{W}\right)$} \\
\hline $2 \& 3$ & & $\%$ & $2 \%$ & 10 & & & & & \\
\hline $4 \& 5$ & & $\%$ & $3 \%$ & $\%$ & & & & & \\
\hline $6 \& 7$ & & $\%$ & $3 \%$ & $\%$ & & & & & \\
\hline $8 \& 1$ & & $\%$ & $1 \%$ & $\%$ & & & & & \\
\hline
\end{tabular}




\section{MJO Precipitation Rate Anomaly}

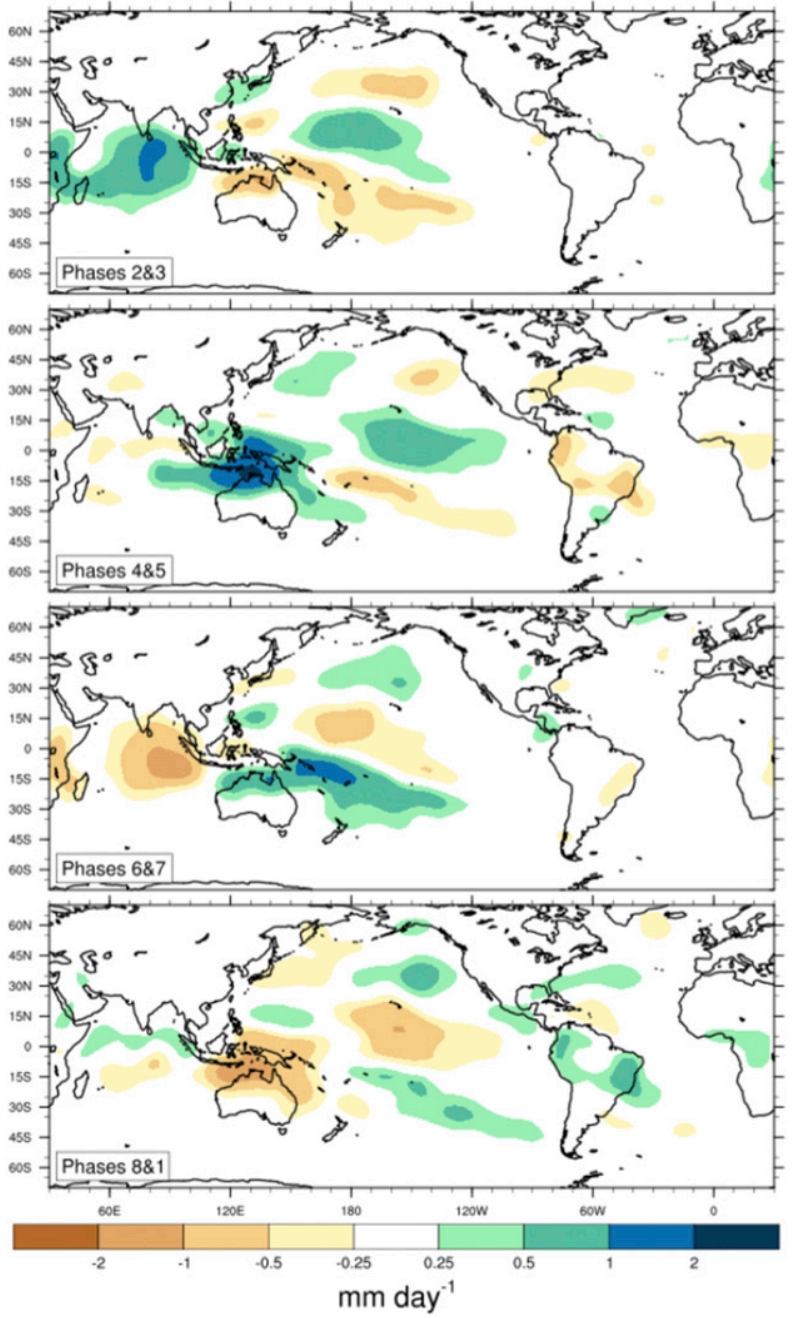

FIG. 2. Spatial pattern of the NCEP-NCAR reanalysis filtered rainfall anomaly showing the eastward propagation of MJO. Blue (brown) shading indicates enhanced (suppressed) precipitation rate $\left(\mathrm{mm} \mathrm{day}^{-1}\right)$. The number of days averaged in each panel from (top) phases $2 \& 3$ to (bottom) phases $8 \& 1$ is $1218,1000,1206$, and 1024 , respectively.

midlatitude jet stream in the central-eastern North Pacific. The 200-mb geopotential height anomalies are investigated further over the United States (see Fig. 10), which breaks down the anomalies not only by MJO phase, but also by ENSO phase. These breakdowns are analyzed further in section $3 \mathrm{c}$.

Previous studies have shown the significant role that moisture advection plays in the dynamics of the MJO (Wang et al. 2015; Jiang et al. 2016; Jiang 2017). Concurrent moist conditions with geopotential height and precipitation anomalies are analyzed to fully explain the rainfall teleconnection response associated with the MJO. The vertical structure of moisture is shown in Fig. 5, displaying both the vertical structure of specific humidity (left) and the moisture flux convergence (right). Anomalies that exceed two standard deviations are shaded (i.e., \pm 2 STDs from the average). There are negative specific humidity anomalies in phases $2 \& 3$ and $4 \& 5$ corresponding to the negative precipitation anomalies seen in the anomalous jet entrance region of the anomalous geopotential height dipole. Conversely, positive specific humidity anomalies are found in the jet entrance region of the anomalous geopotential height dipole in phases $6 \& 7$ and $8 \& 1$. Thus, the geopotential height and horizontal wind anomalies forced by the MJO result in modifications of both the magnitude and extent of the North Pacific climatological jet.

The moisture flux convergence (MFC) was calculated using the horizontal advection terms from the moisture budget:

$\mathrm{MFC}=\int-(\mathbf{v} \cdot q) d p=\int-\left(u \frac{\partial q}{\partial x}+v \frac{\partial q}{\partial y}+q \frac{\partial u}{\partial x}+q \frac{\partial v}{\partial y}\right) d p$,

where $\mathbf{v}$ is the horizontal wind vector, $q$ is specific humidity, and $p$ is pressure. Moisture flux convergence occurs in the anomalous jet entrance region from the geopotential height dipole in phases $6 \& 7$ and $8 \& 1$, concurrent with the positive precipitation anomalies observed. Similarly, there is moisture flux divergence (i.e., negative moisture flux convergence) in the jet entrance region in phases $2 \& 3$ and $4 \& 5$ corresponding to the negative specific humidity and negative precipitation anomalies.

Focusing on the southeastern United States, we notice an analogous pattern of geopotential height anomalies of opposing sign and accompanying rainfall, but of weaker magnitude. In phases $2 \& 3$, the dipole is negativepositive in the north-south direction, and there is a corresponding positive rainfall anomaly (Fig. 4). Phases $6 \& 7$ show the opposite dipole pattern and consequently a negative rainfall anomaly. Figure 6 shows the composites of low-level meridional moisture transport at $850 \mathrm{mb}$ over North America, defined as $\mathbf{v} \cdot q[\mathbf{v}$ is the meridional wind vector $\left(\mathrm{m} \mathrm{s}^{-1}\right)$ and $q$ is specific humidity $\left.\left(\mathrm{g} \mathrm{kg}^{-1}\right)\right]$, and broken down by MJO phases for November-April. The southeastern United States in phases $8 \& 1$ is affected by anomalous southwesterly winds along the southern flank of a strong anomalous cyclone and the northern flank of an anomalous anticyclone (Fig. 4), enhancing the moisture supply from the Gulf of Mexico and the Caribbean Sea to the region (Fig. 6). Additionally, there is a positive specific humidity anomaly and moisture flux convergence in the region (Fig. 5). These are favorable factors for the enhanced rainfall anomaly shown in the southeastern United States in phases $8 \& 1$. A similar pattern over the southeastern United States occurs in phases $2 \& 3$, but to a 


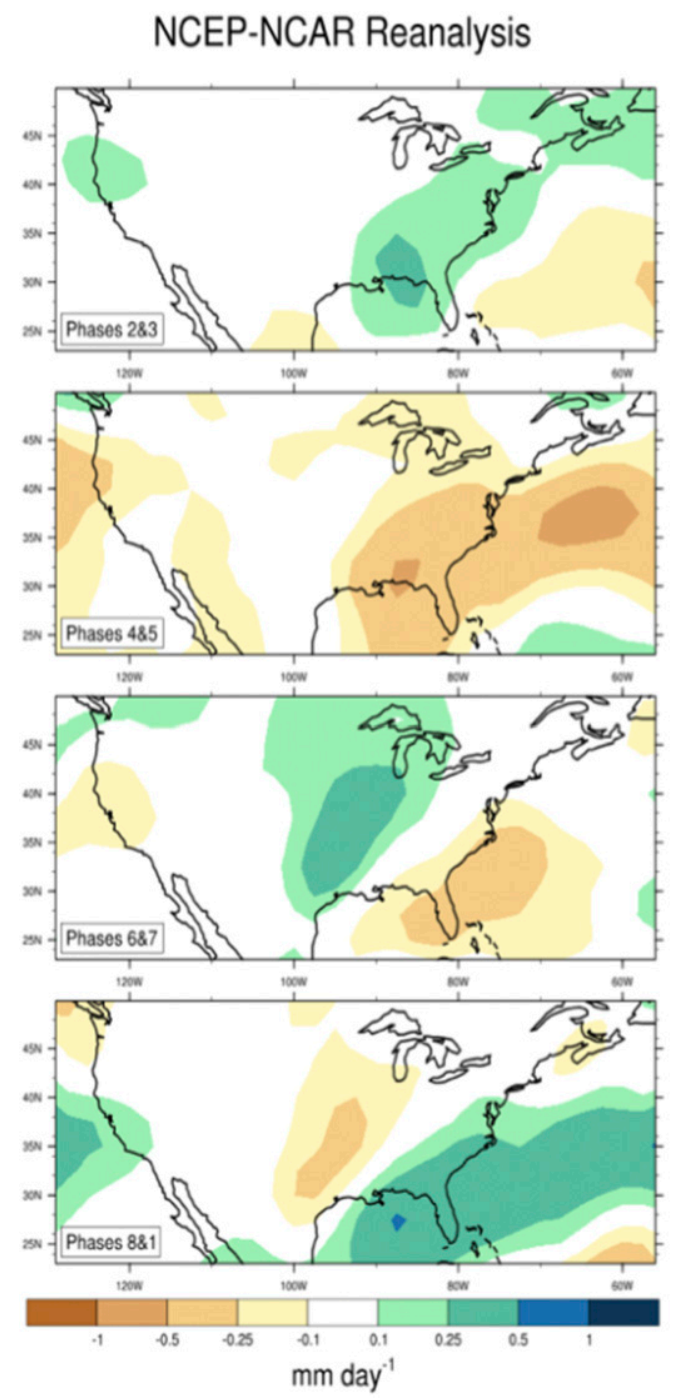

CPC Unified Gauge-Based Analysis
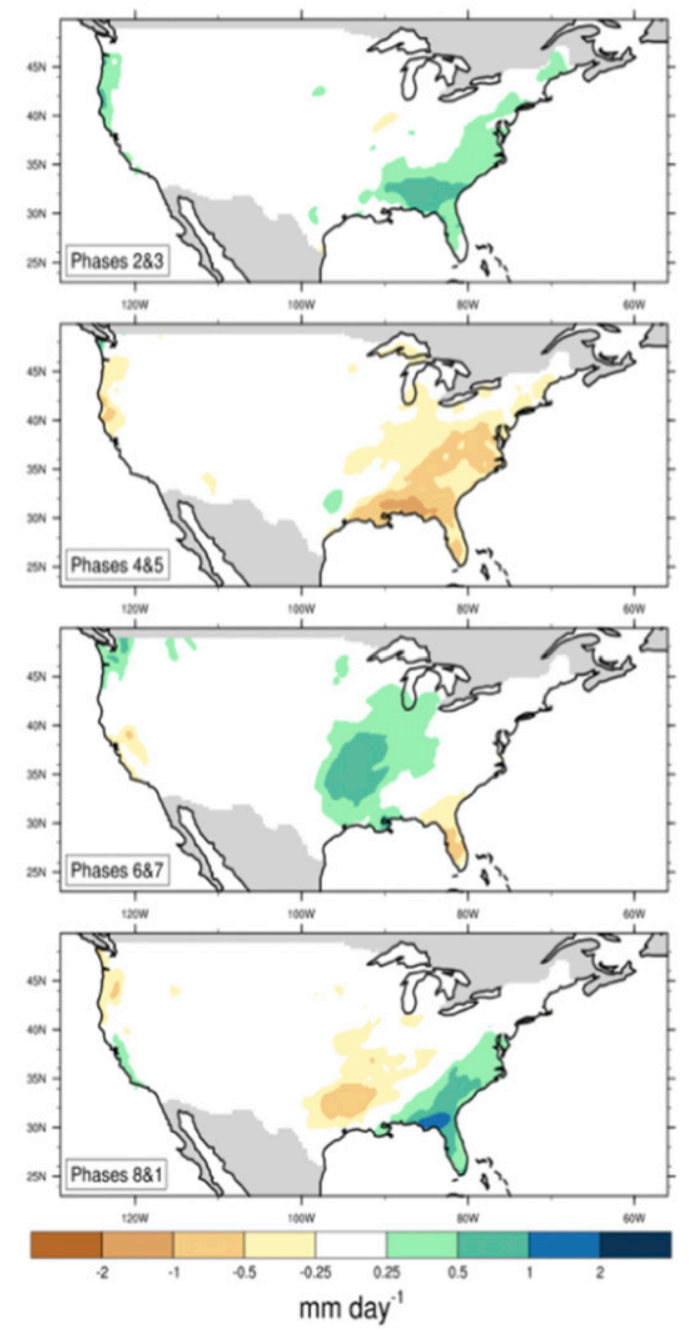

FIG. 3. Comparison of (left) NCEP-NCAR reanalysis precipitation data vs (right) CPC precipitation data for the November-April season from 1979 to 2017. The number of days in each panel as in Fig. 2.

weaker extent as the geopotential height dipole is weaker and located farther northwest than in phases $8 \& 1$. Opposite phenomena conducive to the decreased rainfall in the region tend to appear for phases $4 \& 5$ and $6 \& 7$, showing a prevailing anomalous anticyclone and anomalous northeasterly winds (Fig. 4), negative moisture flux and specific humidity, and moisture flux divergence (Figs. 5 and 6).

Overall, the mechanism behind the North American rainfall teleconnection to the MJO tropical forcing is twofold: 1) perturbations in the upper-tropospheric flow patterns produced by the outflow of the MJO tropical convection, and 2) anomalous regional moisture transport leading to a wetter (drier) atmosphere, which is more conducive to positive (negative) rainfall anomalies.

The statistical significance of the precipitation anomalies associated with the MJO is evaluated in Fig. 7. The figure shows the ratio of precipitation variances between the active and inactive MJO days between 1979 and 2017 , or in other words, the relative importance of rainfall anomalies not associated with the MJO. The $p$ value, defined as the variance ratio, is the probability that we obtain results that are at least extreme as the results we observed, given the null hypothesis that there is no difference in precipitation anomalies for active and inactive MJO days. The variance ratios were computed for both active and inactive MJO days then combined into one dataset, from which all possible permutations are drawn. A new variance ratio was computed and this step was repeated 1000 times. Thus, the $p$ value (variance ratio plotted) is the number of times the recorded differences in the ratio of variances were more extreme than the differences 


\section{MJO Precipitation Rate and 200mb Geopotential Height Anomalies}

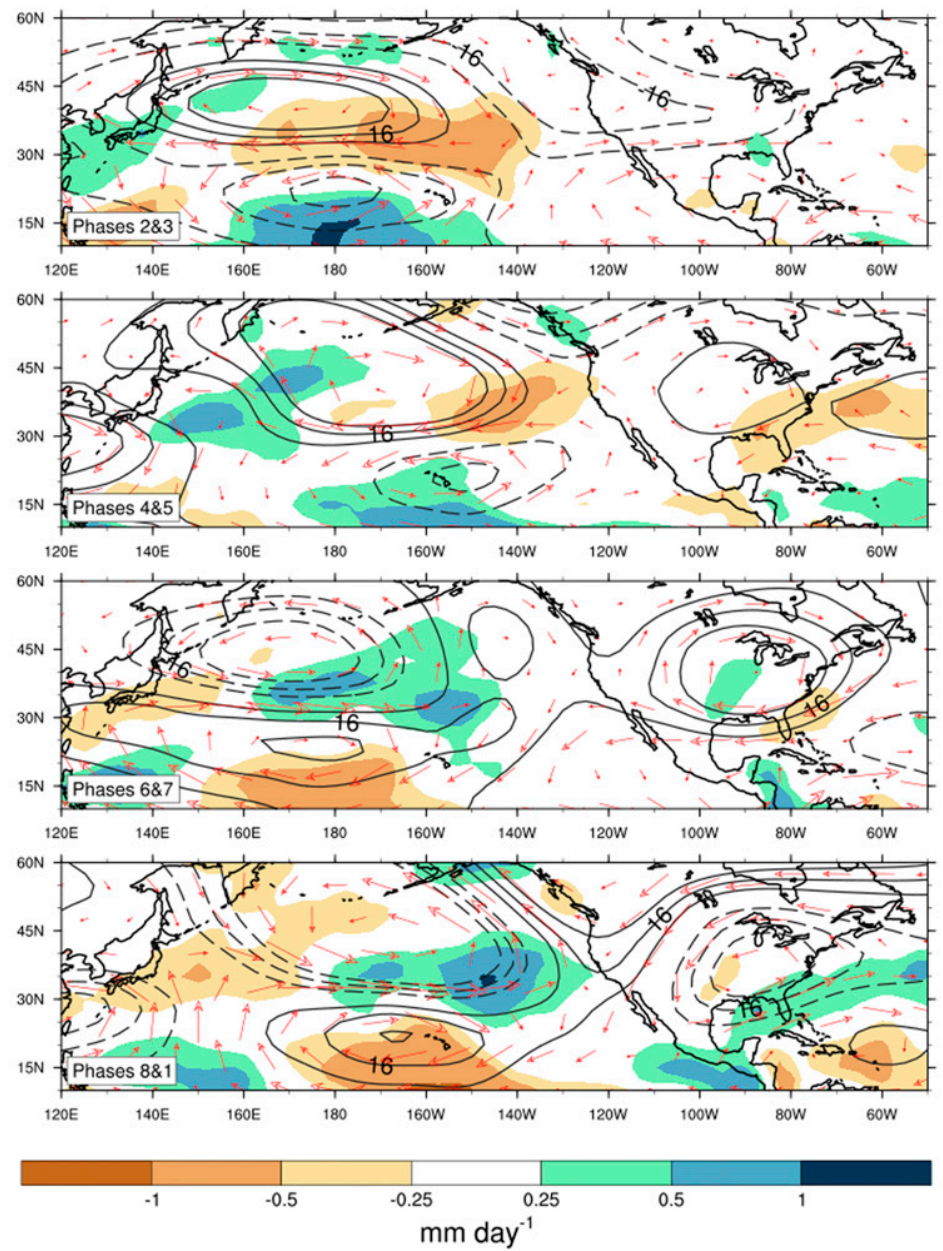

FIG. 4. NCEP precipitation-rate anomaly $\left(\mathrm{mm} \mathrm{day}^{-1}\right)$ broken down by MJO phase. Gray contour overlays are the NCEP 200-mb geopotential height anomalies; contours are from -24 to $24 \mathrm{~m}$ in increments of $8 \mathrm{~m}$. Dashed lines indicate negative anomalies. Red vectors are the $200-\mathrm{mb}$ wind vector anomalies $\left(\mathrm{m} \mathrm{s}^{-1}\right)$.

in the original sample, divided by the total number of permutations.

A ratio of 1 indicates that the precipitation variance of active and inactive days is the same. However, a green region with a 1.2 variance ratio means that the variance is $20 \%$ higher during active MJO days than inactive MJO days in that region. Similarly a brown region with a 0.7 variance ratio means that the variance is $30 \%$ lower during active MJO days than inactive MJO days. The central Mississippi River basin region and southern East Coast all show significantly (at $90 \%$ confidence) higher variance during active MJO days than inactive MJO days. The figure highlights those regions in the United States where an active MJO has the most influence, as the explained variance in some regions can increase notably when the MJO is active. The higher magnitude of explained variance, compared to inactive MJO days, highlights the significant contribution of the MJO signal to subseasonal variability in rainfall in the United States.

\section{c. ENSO interference}

The MJO propagates eastward along the tropical Indian and western Pacific Oceans and dominates subseasonal variability (Zhang 2005), whereas ENSO dominates the same region on interannual time scales, but it is a spatially stationary phenomenon. ENSO has teleconnection signals throughout the globe, affecting atmospheric circulation patterns, temperatures, and precipitation (Diaz et al. 2001). A few previous studies (Moon et al. 2011; Roundy et al. 2010) have examined changes in the MJO-related teleconnections during different ENSO basic states. Overall, these studies demonstrate both that the extratropical 

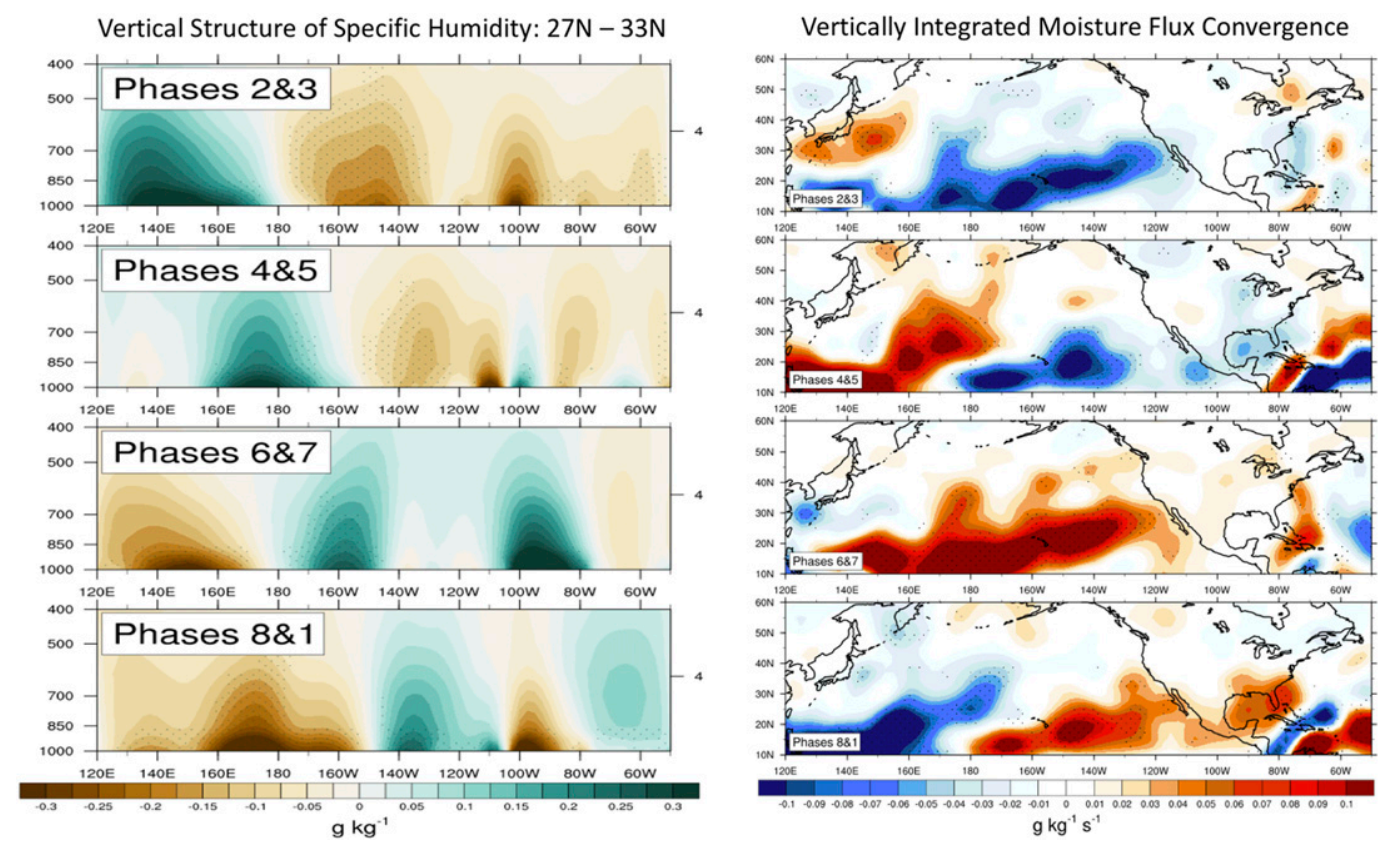

FIG. 5. (left) Vertical structure of the NCEP specific humidity anomalies $\left(\mathrm{g} \mathrm{kg}^{-1}\right)$ averaged over $27^{\circ}-33^{\circ} \mathrm{N}$ with pressure coordinates $(\mathrm{mb})$ on the left axis and height coordinates $(\mathrm{km})$ on the right axis. (right) Vertically integrated moisture flux convergence anomalies $\left(\mathrm{g} \mathrm{kg}^{-1} \mathrm{~s}^{-1}\right.$ ) from the surface to $300 \mathrm{mb}$. A positive anomaly (red) indicates anomalous convergence and a negative anomaly (blue) indicates anomalous divergence. Shaded regions indicate anomalies that exceed two standard deviations.

response to the MJO is enhanced when MJO tropical convection is in phase with heating and convection due to ENSO and that the difference between the El Niño and La Niña teleconnections cannot be explained entirely by a linear superposition of the expected ENSO and MJO signals. We analyze how the MJO teleconnections can affect the persistent signals associated with the ENSO teleconnections to determine if the MJO can provide a source of predictability within an ENSO phase. By including the dominant mode of tropical interannual variability, an explanation of the extratropical rainfall response with concurrent ENSO and MJO phases is proposed.

We analyze each signal to determine where the ENSO and MJO signals constructively or destructively interfere to produce North American precipitation anomalies. The methodology section describes the approach for removing the interannual signal from the data via subtraction of the centered 120-day mean of the anomaly. Therefore, the interannual signal and subseasonal signal are separated, but they are not necessarily linearly independent. El Niño (warm) and La Niña (cold) ENSO periods are defined by the NOAA Climate Prediction Center (CPC): exceeding a threshold of $\pm 0.5^{\circ} \mathrm{C}$ for the oceanic Niño index (ONI), a 3-month running mean of ERSST.v5 SST anomalies in the Niño-3.4 region $\left(5^{\circ} \mathrm{N}-\right.$ $\left.5^{\circ} \mathrm{S}, 120^{\circ}-170^{\circ} \mathrm{W}\right)$, based on centered 30 -yr base periods updated every 5 years. Since each MJO phase corresponds to approximately 8 days and each panel contains 2 phases, or $\sim 16$ days, a lag due to the time needed for the stationary Rossby wave to fully develop can be disregarded.

The time-averaged constructive and destructive interference from the CPC precipitation dataset is shown in Figs. 8, 9,11-13, and 15 . The composites include all days from 1979 to 2017 during either El Niño or La Niña basic states, and that concurrently exceeded one standard deviation on the MJO index. The left columns in these figures show the composite subseasonal anomalies in the United States during warm (El Niño; Figs. 8, 11, and 12) and cold (La Niña; Figs. 9 and 13) ENSO episodes, where the aforementioned MJO teleconnections can be well identified. Figure 10 is simlar to Figs. 8 and 9, but for 200-mb geopotential height anomalies. These panels show the impacts of the MJO teleconnections change for different ENSO basic states during the particular MJO phases. Although the interannual variability has been removed via subtraction of the centered 120-day running mean, the existence of ENSO-induced seasonal anomalies in the extratropical background state can substantially modify the analyzed MJO teleconnections. The center columns show the rainfall associated with the interannual variability dependent on ENSO phase. Thus, for simplicity, the center columns 
MJO Precipitation Rate and $850 \mathrm{mb}$ Moisture Transport Anomalies
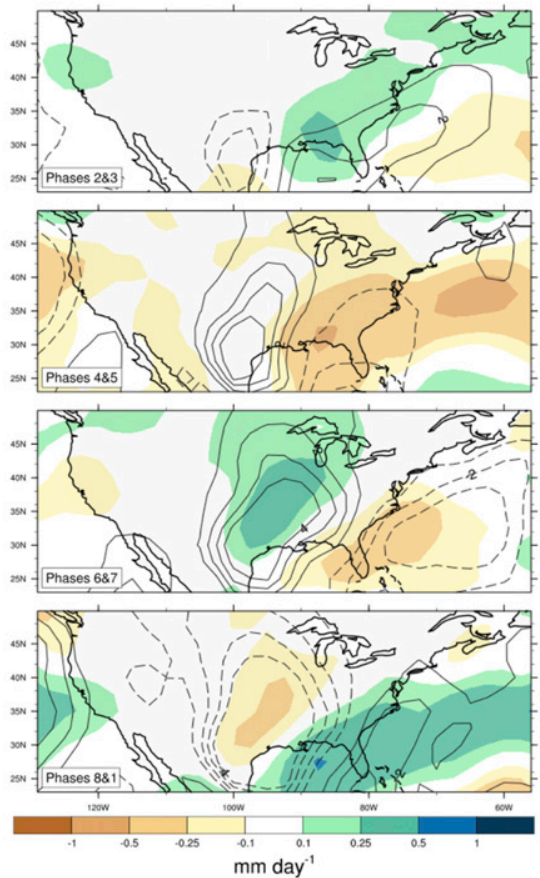

FIG. 6. NCEP precipitation-rate anomaly $\left(\mathrm{mm} \mathrm{day}^{-1}\right)$ broken down by MJO phase. Gray contour overlays are the NCEP 850-mb meridional moisture transport anomalies; contours are from -16 to $16 \mathrm{~m} \mathrm{~s}^{-1} \mathrm{~g} \mathrm{~kg}^{-1}$ in increments of $2 \mathrm{~m} \mathrm{~s}^{-1} \mathrm{~g} \mathrm{~kg}^{-1}$. Dashed lines indicate negative anomalies.

have been titled with the corresponding ENSO phase. The center columns show the precipitation anomalies calculated from the centered 120-day mean, or the part that was removed from the MJO signal, but broken down into the MJO phases. Since ENSO operates on an interannual time scale, the variation and magnitude of corresponding anomalies on a daily time scale is small. The right columns are the sum of the two signals to examine interference of the signals, which is the total anomaly for each MJO phase during all $\mathrm{El}$ Niño or La Niña events. The same number of days in each figure is used for each phase of the MJO; it is only the anomaly being composited that changes from the rows of panels. The composites are therefore doubly conditional in that the days used for the composite are those for a specific ENSO phase and in which the MJO was active.

Figure 8 composites the rainfall for every day from 1979 to 2017 during El Niño events then further broken down by MJO phase. Figure 8a is a composite of the MJO-forced anomaly of all days between November and April from 1979 to 2017 when there was an El Niño event ongoing and the MJO was in phases $2 \& 3$. Figures $8 \mathrm{~d}-\mathrm{f}$ show all winter days during El Niño events when the MJO was active in phases $4 \& 5$, and so on. Figure $8 \mathrm{~b}$ represents the rainfall from the same days as in Fig. 8a in which a simultaneous El Niño event and the MJO in phases $2 \& 3$ occurred; however, it is a composite of only the interannual anomaly associated with El Niño based on the centered 120-day mean of the data. Figure 8c shows the same days composited for Figs.8a,b, but summing the MJO and ENSO anomalies. Thus, Fig. $8 \mathrm{c}$ is the total rainfall anomaly averaged over all days when the MJO was in phases $2 \& 3$ during an El Niño event from November to April during 1979-2017.

In general, a positive rainfall anomaly is expected during an El Niño in California and the Southeast United States, especially Florida. For phases $6 \& 7$ (i.e., Figs. $8 \mathrm{~g}-\mathrm{i}$ ), there is constructive interference in the Gulf states (Fig. 8i) that results in a rainfall anomaly of about triple the magnitude than that from the El Niño signal (Fig. 8h) alone. There is also constructive interference, mostly over Florida, in phases $2 \& 3$ and $8 \& 1$. However, during phases $4 \& 5$ and $8 \& 1$ there is predominantly destructive interference in the Gulf states and centralsouthern Florida in phases $4 \& 5$. Texas, for example,

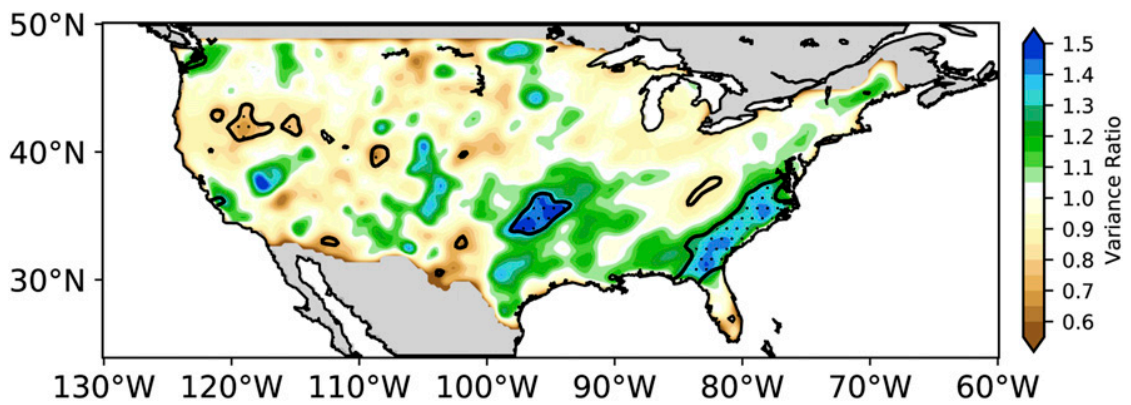

FIG. 7. Ratio of the precipitation variances between the active and inactive winter MJO days between 1979 and 2017 using a permutation test with 1000 iterations. The variance ratio shows the percentage of increased or decreased precipitation variance that occurs on active winter MJO days vs inactive winter MJO days. The significant (at the $90 \%$ level) regions are highlighted by solid black contours and are stippled within. 

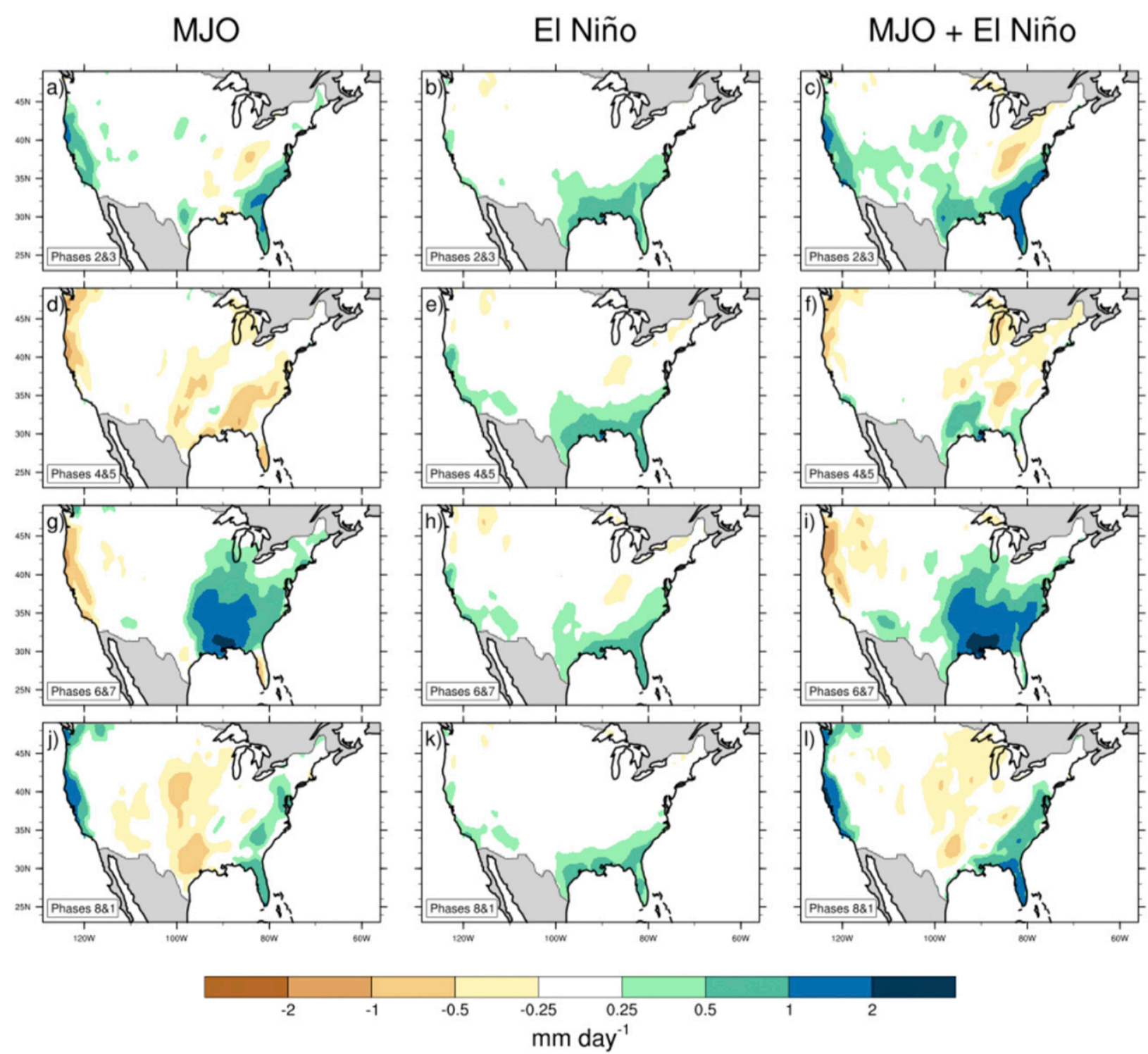

FIG. 8. Composites of CPC precipitation $\left(\mathrm{mm} \mathrm{day}^{-1}\right)$ broken down by MJO phase from 1979 to 2017 for active MJO days in NovemberApril during all El Niño (positive ENSO) days. The columns show (left) MJO-only rain, (center) ENSO-only rain, and (right) MJO + ENSO rain. The number of days averaged in each panel from (top) phases $2 \& 3$ to (bottom) phases $8 \& 1$ is $433,311,358$, and 343 , respectively.

has a negative rainfall anomaly forced from the MJO (Fig. 8d) but a positive anomaly forced from ENSO (Fig. 8e), which results in a very small negative anomaly when combining the influences from the two signals (Fig. 8f). The interference shows that the MJO has a large effect on the rainfall teleconnections on a daily time scale.

Figure 9 shows the composited rainfall for the days that exceeded one standard deviation on the MJO index and occurred during La Niña events from November to April during 1979-2017. Therefore, there are two conditions that must be met for the composite and the days are grouped by the phase of the MJO. The left column shows the MJO-forced anomaly for the La Niña basic state and for the individual MJO phases, the center column shows the ENSO-related anomaly, and the right column shows the interference, or the sum of the left and center columns for the same days.

During a La Niña event, the expected teleconnection response is anomalous dryness in California and the Southeast United States. Phases $4 \& 5$ (Figs. 9d-f) show constructive interference of both negative anomalies from the MJO and ENSO signals in the Gulf states, resulting in considerable dryness in the region. However, in 

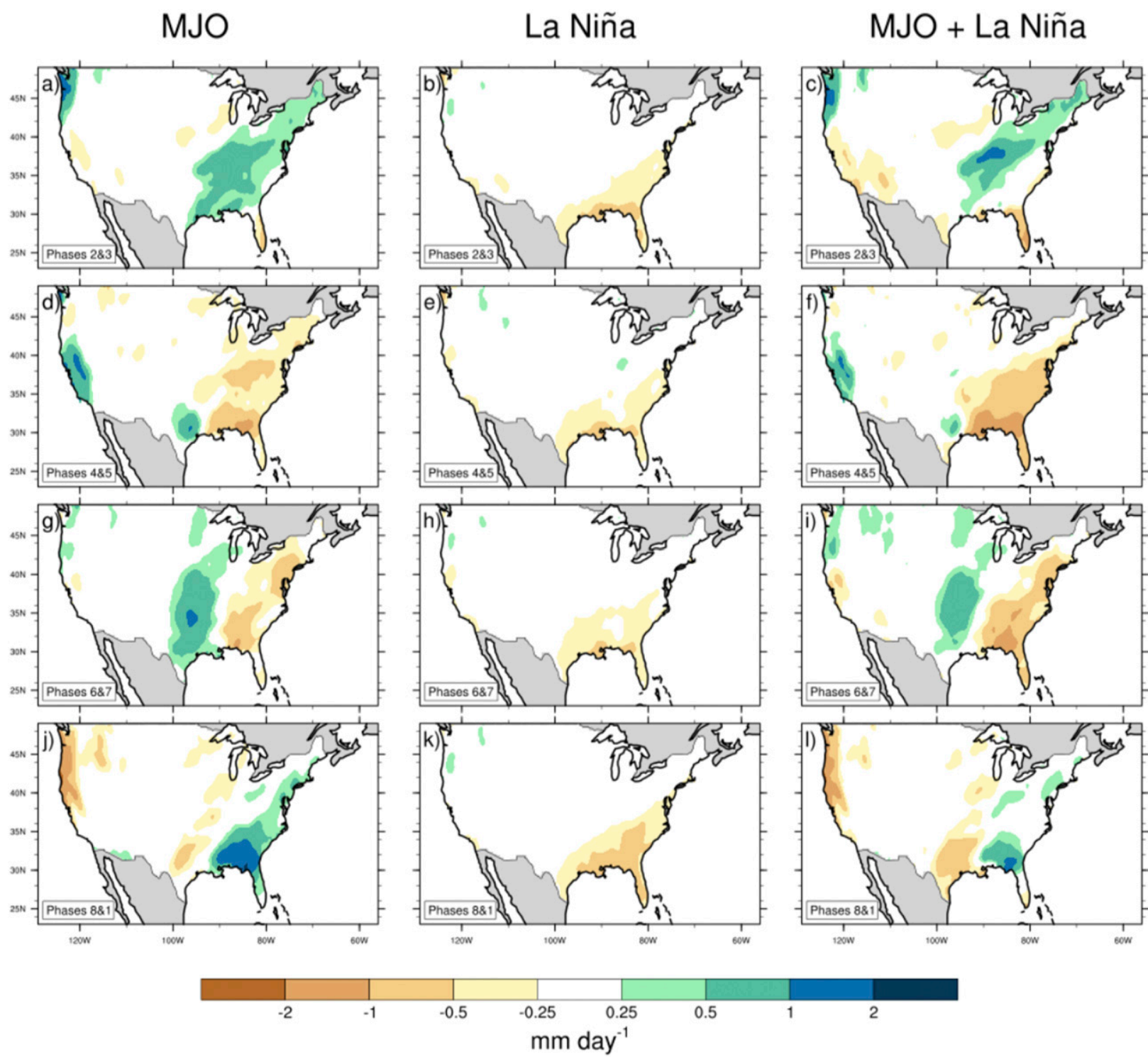

FIG. 9. As in Fig. 8, but for La Niña (cold ENSO) days. The number of days averaged in each panel from (top) phases $2 \& 3$ to (bottom) phases $8 \& 1$ is $382,352,402$, and 284 , respectively.

phases $8 \& 1$ (Figs. 9j-1), the MJO signal brings positive precipitation anomalies to the central Gulf states (Georgia and Alabama), while La Niña brings negative anomalies to the region. During this cold ENSO phase, the MJO signal overwhelms the interannual variability signal expected from ENSO via destructive interference, and the result is positive precipitation anomalies in that region.

These precipitation patterns can be further investigated through analysis of the 200-mb geopotential height anomalies. Figure 10 shows the breakdown of the 200-mb geopotential height anomalies for both El Niño and La Niña days (similar to Figs. 9 and 10). In phases $2 \& 3$ for both El Niño and La Niña days, a negative geopotential height anomaly in the western United States is strengthened by constructive interference with the ENSO signal (Figs. 10a-c, m-o). This results in southwesterly flow over the warm Gulf of Mexico which corresponds to a positive precipitation anomaly in the Southeast United States. The dry anomaly in the southern area of the United States in phases $8 \& 1$ (Figs. $10 \mathrm{j}-1, \mathrm{v}-\mathrm{x}$ ) can be associated with the geopotential dipole which constructively interferes to bring a northeasterly flow to the region. Phases $2 \& 3$ and $8 \& 1$ during El Niño (Figs. 10a-c, j-1) act to extend the jet over the west coast and strengthen over the Southeast United States. Phases $6 \& 7$ (Figs. 10g-i) shows warmer and wet conditions in the East and Gulf 


\section{$200 \mathrm{mb}$ Geopotential Height Anomalies}
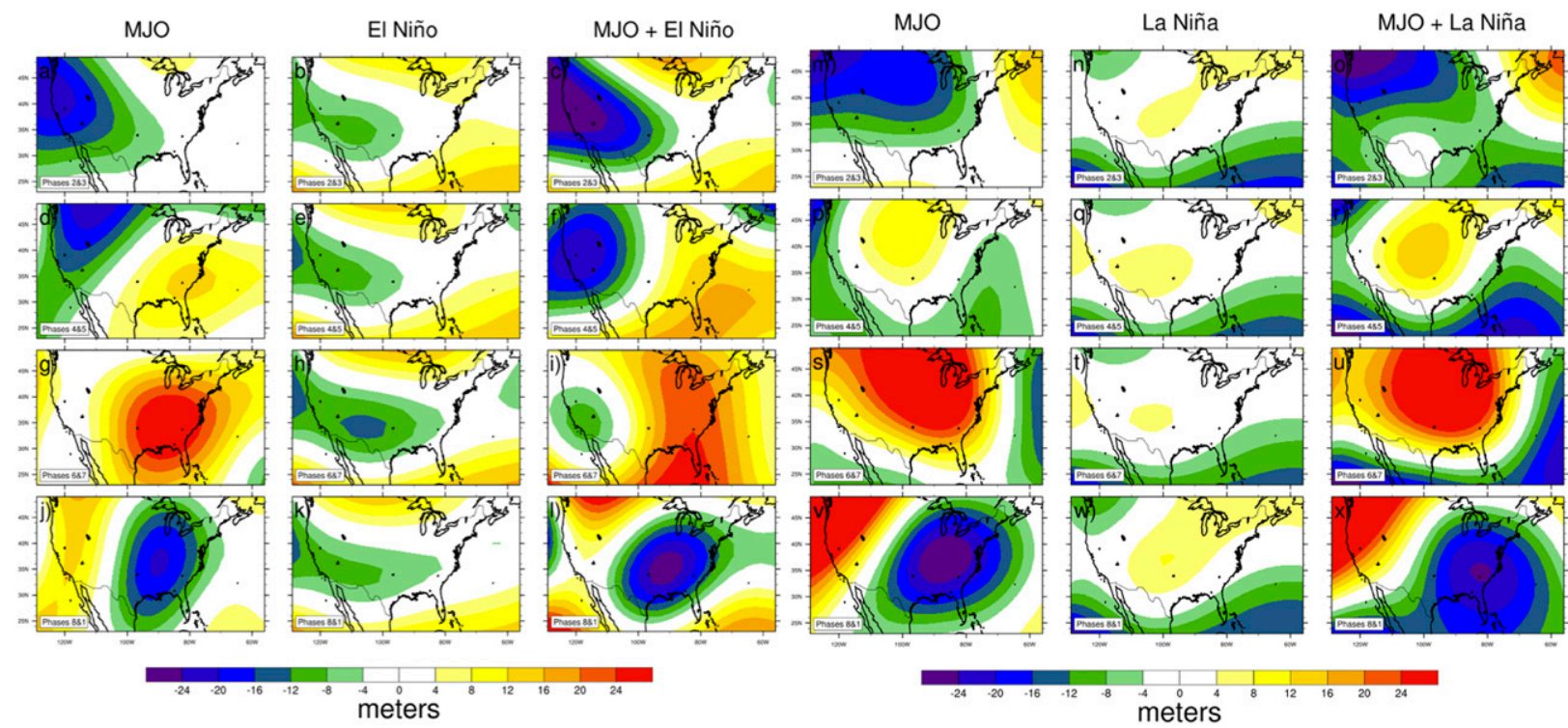

FIG. 10. NCEP 200-mb geopotential height anomalies (m) broken down by MJO phase from 1979 to 2017 for active MJO days in November-April during (left) all El Niño (positive ENSO) days and (right) all La Niña (negative ENSO) days.

states and the El Niño signal reinforces wet conditions in the East.

Phases $4 \& 5$ and $6 \& 7$ of the MJO during La Niña (Figs. 10p-u) act to weaken the jet in the Southeast and East United States, leading to dry conditions in these regions. Phases $8 \& 1$ during La Niña (Figs. 10v-x) show destructive interference with opposing effects on the jet stream over the southeastern states, bringing cold and dry conditions to the West Coast. The joint influence of both the MJO and ENSO on the circulation patterns advects air through regions which warm and moisten or cool and dry the air, corresponding to the precipitation anomalies seen.

The responses from individual El Niño and La Niña events prove to be highly variable. The 1997/98 El Niño event was a particularly strong warm event and the MJO phase breakdowns are plotted in Fig. 11. The composites show the MJO phases for all days during the November 1997/April 1998 El Niño event that also exceeded one standard deviation on the MJO index. The entire November-April 1997/98 season is used for this case study, because the entire season was categorized as a positive ENSO phase according to the NOAA Climate Prediction Center criteria. Figure 11a composites the MJO-forced anomaly (the seasonal cycle and 120-day running mean removed) in which the MJO was in phases $2 \& 3$. The center column composites the anomaly associated only with El Niño (i.e., the centered 120day running mean), and the right column is the sum of the MJO and El Niño anomalies broken down by MJO phase.

In the Gulf states, particularly Florida, and in California, we see the expected positive rainfall anomalies during an El Niño event. In phases $4 \& 5$, however, the MJO signal is strongly negative in California, denoted by the black boxes in the panels. There is destructive interference between the MJO and ENSO signals. The MJO signal dominates the teleconnection response and the result is a negative rainfall anomaly in California. Consequently, the negative rainfall teleconnection response in California from the MJO was weakened by the positive rainfall teleconnection response from El Niño. Conversely, in phases $6 \& 7$ (Figs. 11g-i) in the Gulf states, there is strong constructive interference between the MJO and El Niño signals, also denoted by the black boxes. Particularly along the southern East Coast, the positive rainfall from the combination of both oscillations' teleconnections results in over a doubling of the magnitude of the rainfall anomaly from each individual signal.

Table 1 shows the explained variance of the anomalies for the winter (November-April) precipitation variance for both the California and Gulf regions denoted by the black boxes in the figures for all case studies. The explained rainfall variance in phases $4 \& 5$ in the California region is reduced from $43 \%$ to $18 \%$ due to the destructive interference from the MJO and ENSO signals. Additionally, the constructive interference in the Gulf 

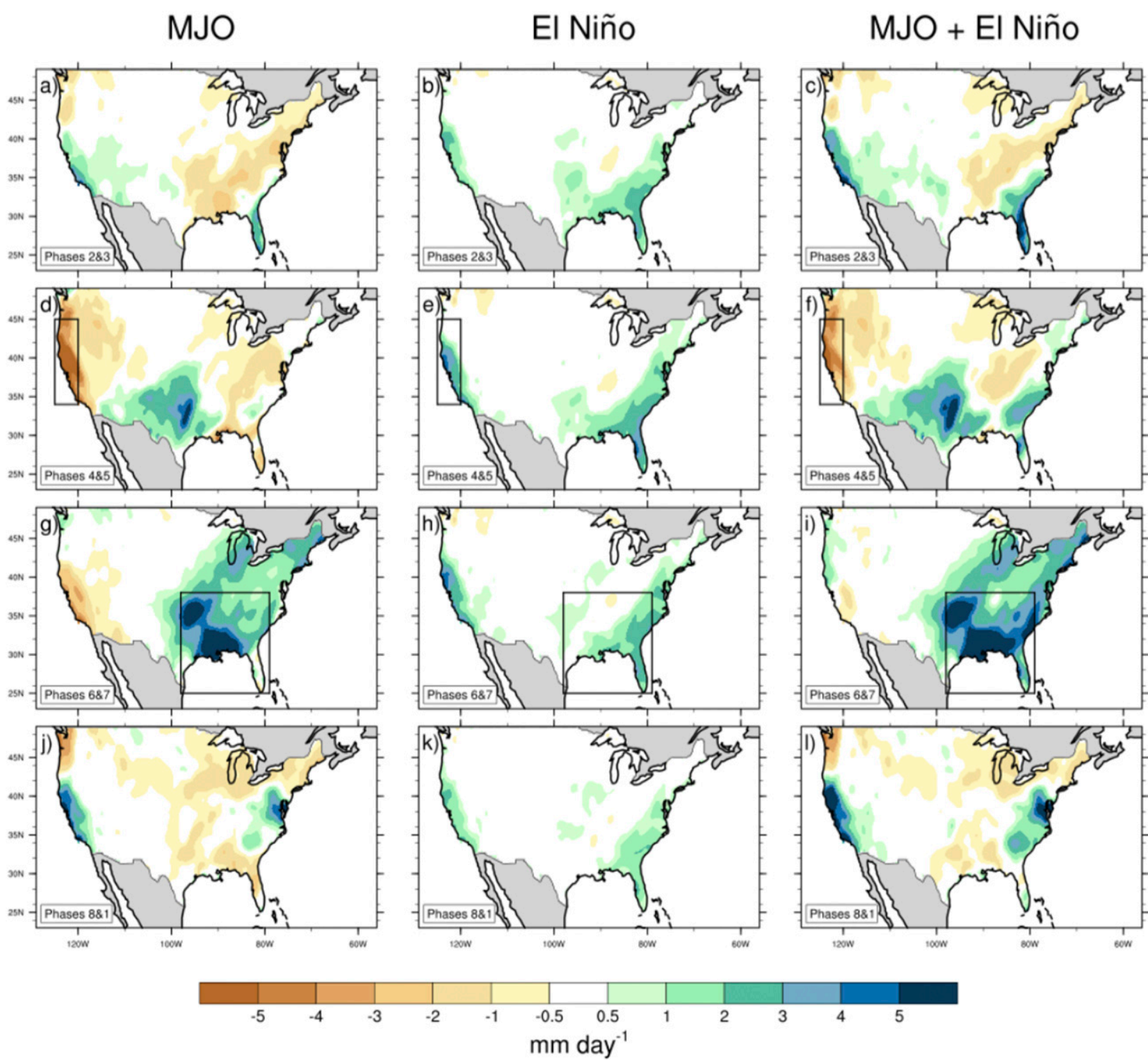

FIG. 11. As in Fig. 10, but for a case study for the November 1997-April 1998 El Niño event. The number of days averaged in each panel from (top) phases $2 \& 3$ to (bottom) phases $8 \& 1$ is $31,16,28$, and 32 , respectively. Black boxes denote prominent areas of constructive or destructive interference. (d)-(f) The California region box in phases $4 \& 5$ outlines $34^{\circ}-45^{\circ} \mathrm{N}, 125^{\circ}-120^{\circ} \mathrm{W}$. (g)-(i) The Gulf region box in phases $6 \& 7$ outlines $25^{\circ}-38^{\circ} \mathrm{N}, 101^{\circ}-82^{\circ} \mathrm{W}$.

region increases the explained variance from $18 \%$ (the MJO alone) to $29 \%$ (the MJO and ENSO signals combined). Table 2 shows the same explained variances, but for the ratio of the anomalies to the total annual rainfall variance. The numbers increase when dividing by the total annual variance, as expected, as this is a less conservative calculation of the ratio of the anomalies attributed to the individual climate modes and their combination to the total variance. The explained variances for the subsequent case studies are also included in Table 1 for the explained variance to winter precipitation variability and in Table 2 for the explained variance to annual precipitation variability.
The El Niño of 2015/16 was a notoriously strong event, with sea surface temperature anomalies of over $2.5^{\circ} \mathrm{C}$ according to the NOAA Climate Prediction Center ONI index. Many had hoped that the 2015/16 El Niño would bring rainfall to California as the state had been in a massive drought since 2012 (Siler et al. 2017). However, California received significantly less rainfall than forecasted and compared with other El Niño events of comparable magnitude (Siler et al. 2017).

Figure 12 shows the breakdown of the MJO and ENSO signals by phase for the November 2015-April 2016 season, in which the El Niño event was at its peak 

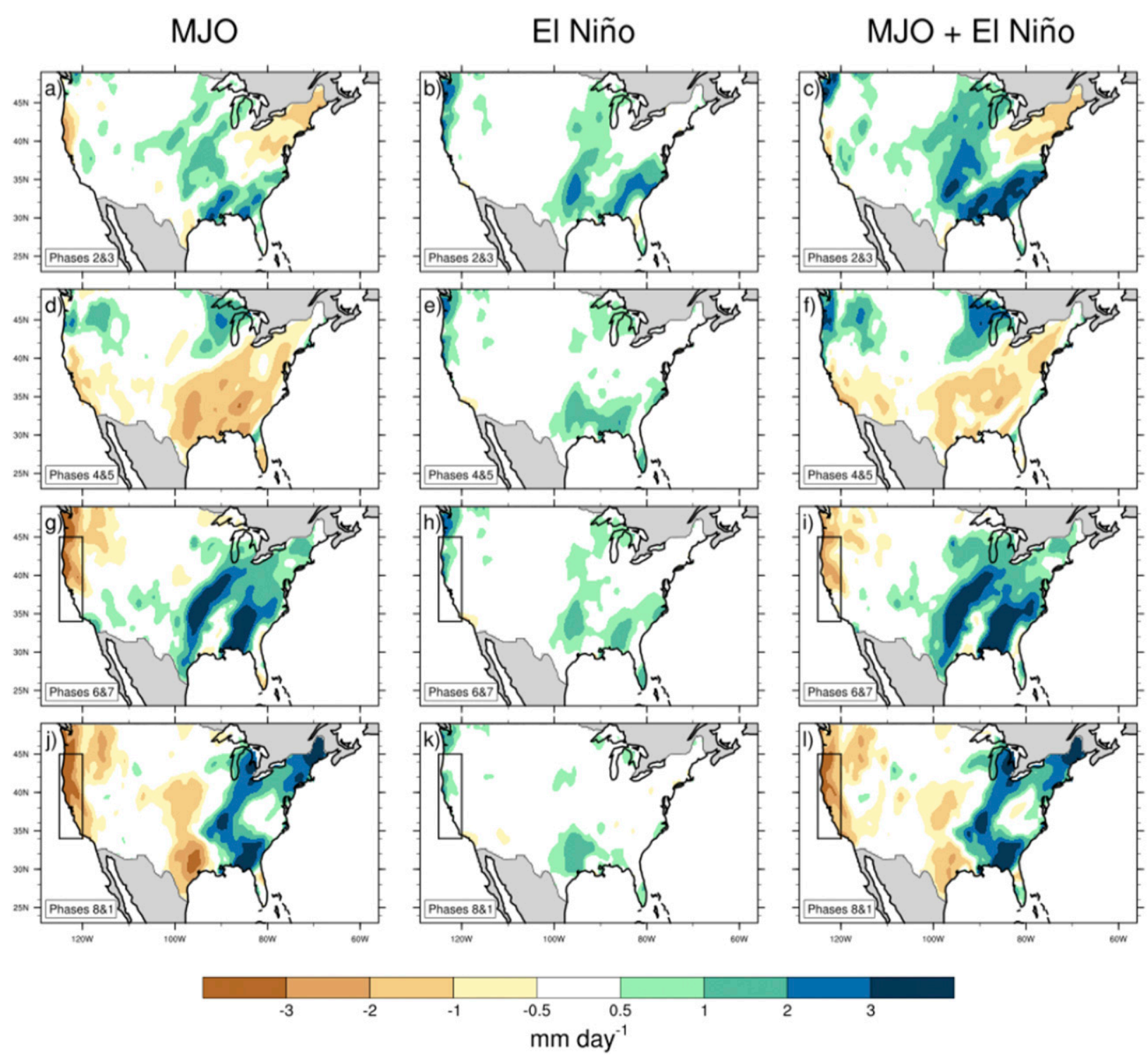

FIG. 12. As in Fig. 8, but for a case study for the November 2015-April 2016 El Niño event. Black boxes denote prominent areas of constructive or destructive interference. The number of days averaged in each panel from (top) phases $2 \& 3$ to (bottom) phases $8 \& 1$ is 38 , 30,26 , and 20, respectively. (g)-(l) The California region boxes in phases $6 \& 7$ and $8 \& 1$ outlines $34^{\circ}-45^{\circ} \mathrm{N}, 125^{\circ}-120^{\circ} \mathrm{W}$.

magnitude. The left column shows the signal associated with just the MJO forcing for active MJO days per phase. The center column shows the same days, but only the signal associated with El Niño. The right column sums the two signals for the same days to show interference. In phases $6 \& 7$ and $8 \& 1$ (Figs. 12g,j), the MJO brought an anomalously dry signal to the entire West Coast of the United States, denoted by a black box. Furthermore, the El Niño signal brought only a slight positive rainfall anomaly to the Pacific Northwest (Figs. 12h,k). The destructive interference of the two signals (Figs. 12i,l) shows that the MJO dominated the teleconnection response, and the result was a $-2 \mathrm{~mm} \mathrm{day}^{-1}$ anomaly along the western United States. The explained variance from the MJO alone was $7 \%$ and $13 \%$ in phases $6 \& 7$ and $8 \& 1$, respectively, and is reduced to $4 \%$ and $10 \%$, respectively, due to destructive interference with the El Niño signal (see Table 1). This analysis shows that it was a combination of both the ENSO signal not bringing the expected rainfall and destructive interference with the MJO signal that resulted in the negative rainfall anomalies in Southern California during the 2015/16 winter.

This conclusion complements the findings of Siler et al. (2017), who note that a possible explanation of the forecast error was anomalous SSTs outside of the 
canonical Niño-3.4 region, particularly in the tropical Indian and western Pacific Oceans, as well as atmospheric noise or chaos (Hoerling and Kumar 1997; Kumar and Hoerling 1997). Paek et al. (2017) find the 1997/98 and 2015/16 El Niños were centered in different regions of the Pacific which could help explain why the events were so different. Yang et al. (2018) note that the different El Niño dynamics in the two events were responsible for changes in atmospheric circulation patterns, perhaps helping to explain the anomalous dryness seen in California during the 2015/16 El Niño event.

The analysis in the current study acts to provide an additional explanation for the dry El Niño in California, as the destructive interference between the ENSO and MJO signals resulted in negative precipitation anomalies during MJO phases $6 \& 7$ and $8 \& 1$. The anomalies seen in California during the 1997/98 and 2015/16 El Niños were both negative during certain MJO phases, yet the MJO appears to have had a larger influence on that anomaly in the 1997/98 event based on the explained variance. The discrepancies in the explained variance of the MJO-associated rainfall from the 1997/ 98 and 2015/16 El Niños also brings into question the variability of the MJO teleconnection within a particular ENSO phase. Accurate modeling of climate modes such as the MJO, as well as atmospheric circulation and sea surface temperature has the potential to improve the subseasonal and seasonal forecasts in regions which experience tropical-extratropical teleconnection responses, such as California. This further highlights the subseasonal variability within an interannual signal.

Figure 13 shows the interference for a strong La Niña event lasting from July 1998 to March 2001. The days composited for this figure were all days in which the MJO was active from November 1998 to April 1999, November 1999 to April 2000, and November 2000 to March 2001, broken down by the MJO phase similarly to the earlier figures. During this event, there was a persistent modest negative rainfall anomaly in the Southeast United States. Phases $6 \& 7$ had strong constructive interference leading to a large negative precipitation anomaly in the Gulf states of over $2 \mathrm{~mm}$ day $^{-1}$ (Fig. 13i). The same region experienced destructive interference in phases $8 \& 1$, leading to negative rainfall anomalies of less than $1 \mathrm{~mm}^{\text {day }}{ }^{-1}$ (Fig. 13l).

The individual El Niño and La Niña events can be examined in more detail by looking at specific envelopes of the MJO occurring simultaneously with an ENSO phase. For example, the central United States saw extreme precipitation in late December 2015, shown in Fig. 14. The white contour lines indicate the regions that received (on average) greater than one standard deviation of precipitation from 14 to 31 December 2015.
During this time period, there was one of the strongest El Niños on record ensuing. The MJO was also active and in phases $4 \& 5$ from 14 to 22 December and in phases $6 \& 7$ from 23 to 31 December 2015. The time series in Fig. 14 shows the daily observed precipitation superimposed with the MJO and ENSO precipitation signals during the flooding period with the corresponding MJO phases highlighted. The MJO signal plotted has a 16-day lowpass filter applied to remove any high-frequency synoptic variability not associated with the MJO that is averaged out in the combined phase composites. Fifteen days before and after the most severe flooding are included for reference of the variability of each climate mode. During the second half of phases $4 \& 5$ and the entirety of phases $6 \& 7$, the MJO and ENSO signals constructively interfered, contributing notably to the extreme rainfall observed.

Figure 15 breaks down the rainfall signals from the MJO and ENSO individually. The left column shows the MJO-forced anomaly (seasonal cycle and 120-day running mean removed) for the 9 days when the MJO was in phases $4 \& 5$ (Fig. 15a) and the 9 days when the MJO was in phases $6 \& 7$ (Fig. 15d). Figures $15 \mathrm{~b}$ and 15e correspond to the same days as Figs. 15a and 15d, respectively, but composite only the ENSO-associated part of the anomaly. Figures $15 \mathrm{c}$ and $15 \mathrm{f}$ show the combined signal from the MJO and ENSO for late December 2015 broken down by the MJO phase.

Combined with a positive rainfall response from ENSO, the MJO signal was enhanced in the northern Great Lakes states and Southeast region, and weakened in Texas. In phases $6 \& 7$ of December 2015, the MJO signal contributed to extremely high precipitation anomalies throughout the central and Southeast United States. This signal constructively interfered with the ongoing ENSO signal, and the central and Southeast United States experienced over $200 \mathrm{~mm}$ of rainfall in just over 2 weeks. The consequences of the record-breaking rainfall were devastating to the affected areas with millions of dollars of damages and over 50 fatalities, making it the deadliest weather event of 2015.

During this time, there was a strong anomalous eastwest geopotential height dipole with anomalous high pressure in the eastern United States and low pressure in the western United States (not shown), very similar to that seen in phases $6 \& 7$ during El Niño events (see Figs. $10 \mathrm{~g}-\mathrm{i}$ ). However, during this case study, both the MJO and ENSO signal led to anomalous high pressure over the eastern United States, and the constructive interference resulted in a stronger dipole. This circulation pattern results in a strong southerly flow, advecting warm moist air from the subtropics and tropics, consistent with the large positive precipitation anomalies. 

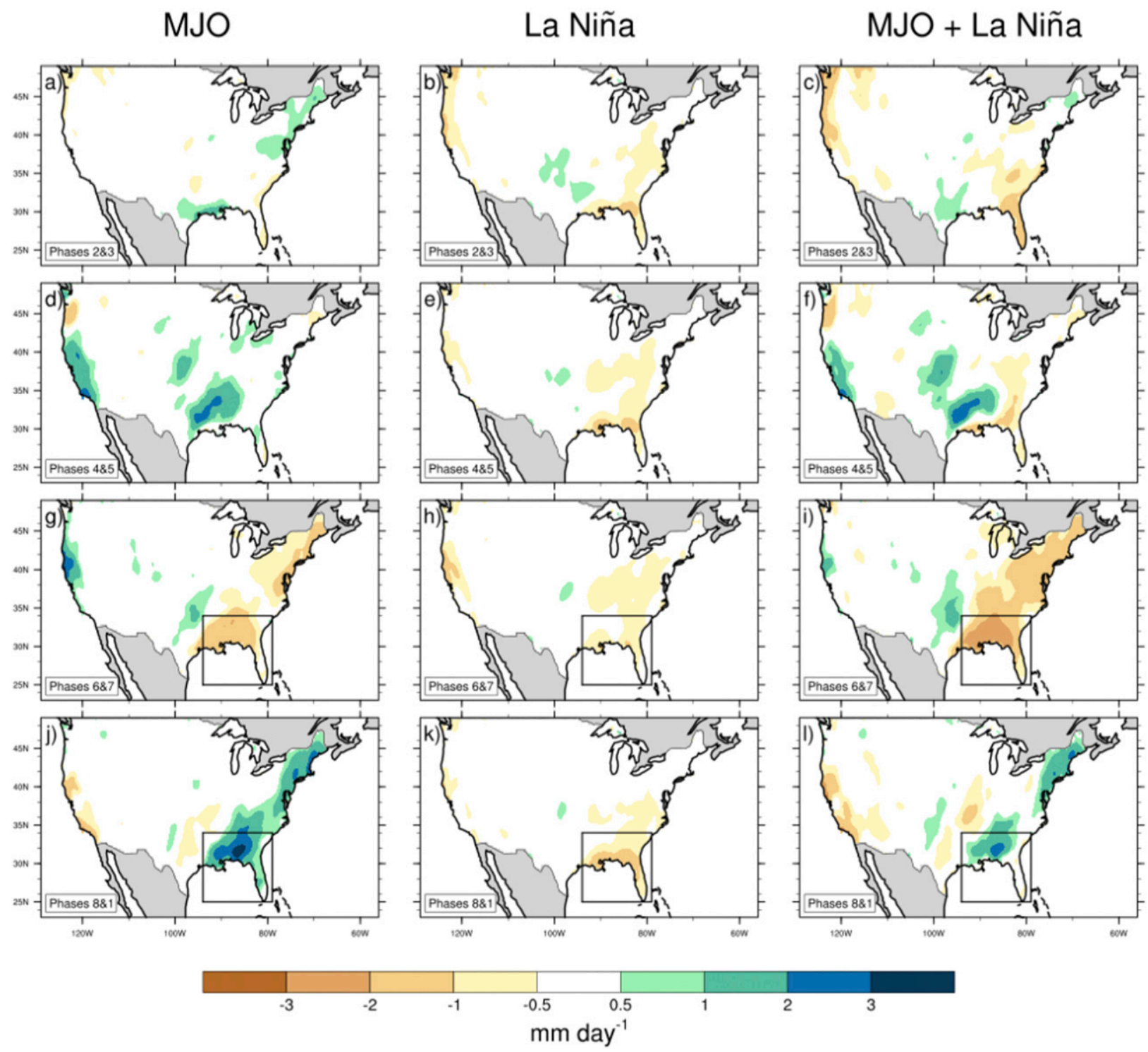

FIG. 13. As in Fig. 11, but for a case study for the November 1998-March 2001 La Niña event. The number of days averaged in each panel from (top) phases $2 \& 3$ to (bottom) phases $8 \& 1$ is $91,72,93$, and 55 , respectively. (g)-(l) The Gulf region boxes in phases $6 \& 7$ and $8 \& 1$ outline $25^{\circ}-34^{\circ} \mathrm{N}, 101^{\circ}-86^{\circ} \mathrm{W}$.

The circulation pattern observed during this strong precipitation event during an active MJO in phases $6 \& 7$ and a positive ENSO phase is consistent with that seen during the average doubly conditional phases (Figs. 10g-i). Since this particular case study resembles the average pattern well, it can lend itself to a potential for predictability as the forecast of opportunity.

These examples highlight how a region with a wellknown teleconnection response from ENSO can experience the opposite precipitation pattern due to an active MJO in a particular phase. The MJO-ENSO interference in the case studies (Figs. 11-13), as well as the total time averages (Figs. 8-10), clearly varies spatially and temporally. Furthermore, the extratropical response from the remote forcing has a strong case-by-case dependence, so their differences cannot be easily explained by the expected MJO phase signal.

\section{d. Implications for predictability}

Due to the far-reaching effects of the tropical convection, the MJO is considered to be one of the largest untapped sources of global predictability on the subseasonal time scale (Lau and Waliser 2011; Stan et al. 2017). Studies suggest that subseasonal climate modes 
Total Precipitation from December 14-31 2015

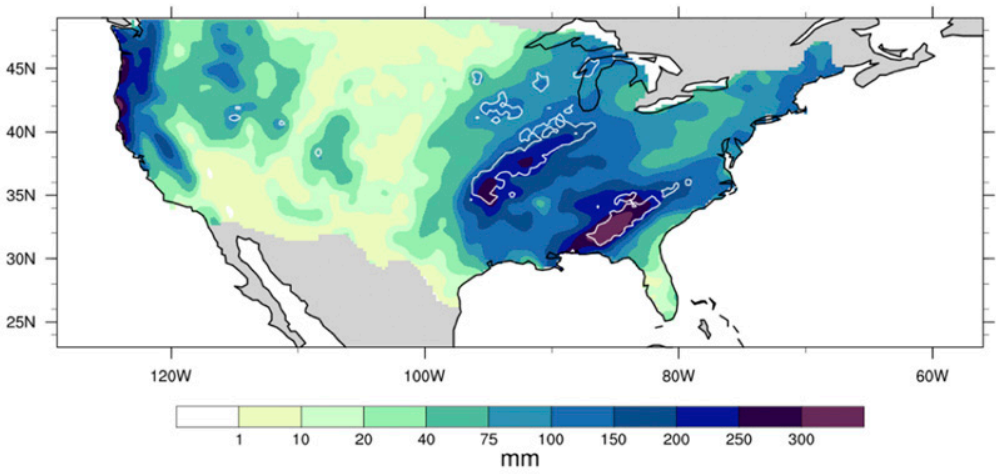

Breakdown of Precipitation in the Central and Southeast U.S. Flooding Region

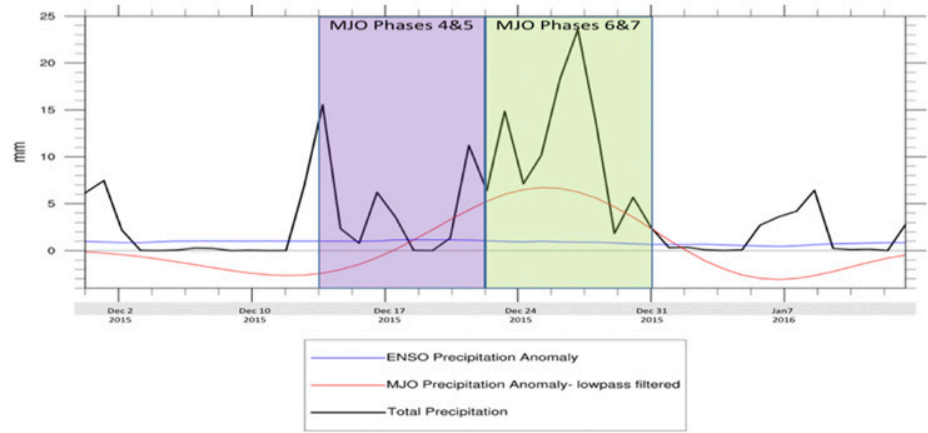

FIG. 14. (top) Total rainfall (mm) from 14 to 31 Dec 2015 from the CPC precipitation dataset during a positive ENSO phase and active MJO. The white contours lines indicate where the precipitation anomaly in the corresponding region exceeded one standard deviation. (bottom) Three time series from 1 Dec 2015 to 15 Jan 2016 . The observed daily precipitation is shown in black, the 16-day low-pass-filtered MJO anomaly in red, and the 120-day centered running mean (e.g., ENSO anomaly) in blue. The days during which the MJO was in phases $4 \& 5$ are shaded in purple, and the days during which the MJO was in phases $6 \& 7$ are shaded in green.

that have known teleconnection patterns can increase model forecast skill for subseasonal climate prediction when the modes are active (Lin and Brunet 2011; Pegion et al. 2019). The joint influences of ENSO and the MJO can also potentially lead to improved predictive skill out to 4 weeks (Riddle et al. 2013; Johnson et al. 2014). Further research of the MJO offers a potential source of rainfall predictability over the United States on subseasonal time scales if the teleconnections can be captured accurately in forecast models.

\section{Conclusions and discussion}

\section{a. Atmospheric circulation and moisture transport}

The Madden-Julian oscillation (MJO) is extracted from interannual and seasonal variability to determine the response of global subseasonal weather patterns, particularly those in North America, to tropical forcing. A multivariate EOF analysis is performed to decompose the MJO into phases depending on the location of deep convection. The extratropical response in the Northern Hemisphere during the MJO active season (November-April) is diagnosed primarily through composite analysis.

We find two contributing factors to the precipitation anomalies in North America. The first are perturbations in the Northern Hemisphere upper-level atmospheric flow. The upper-level jet is retracted or extended by the anomalous geopotential height dipole set up by the quasi-stationary Rossby wave train forced by the MJO tropical convection. There are anomalous precipitation patterns and concomitant upper-level divergence associated with the dipolar pressure anomalies across the North Pacific-North American sector.

The second element conducive of rainfall deviations is the regional anomalous moisture transport and moisture flux convergence. A consistent relationship exists between the upper-level anomalous flow and low-level moisture transport. A simultaneous cyclonic anomaly, acceleration of the jet and upper-level divergence, 


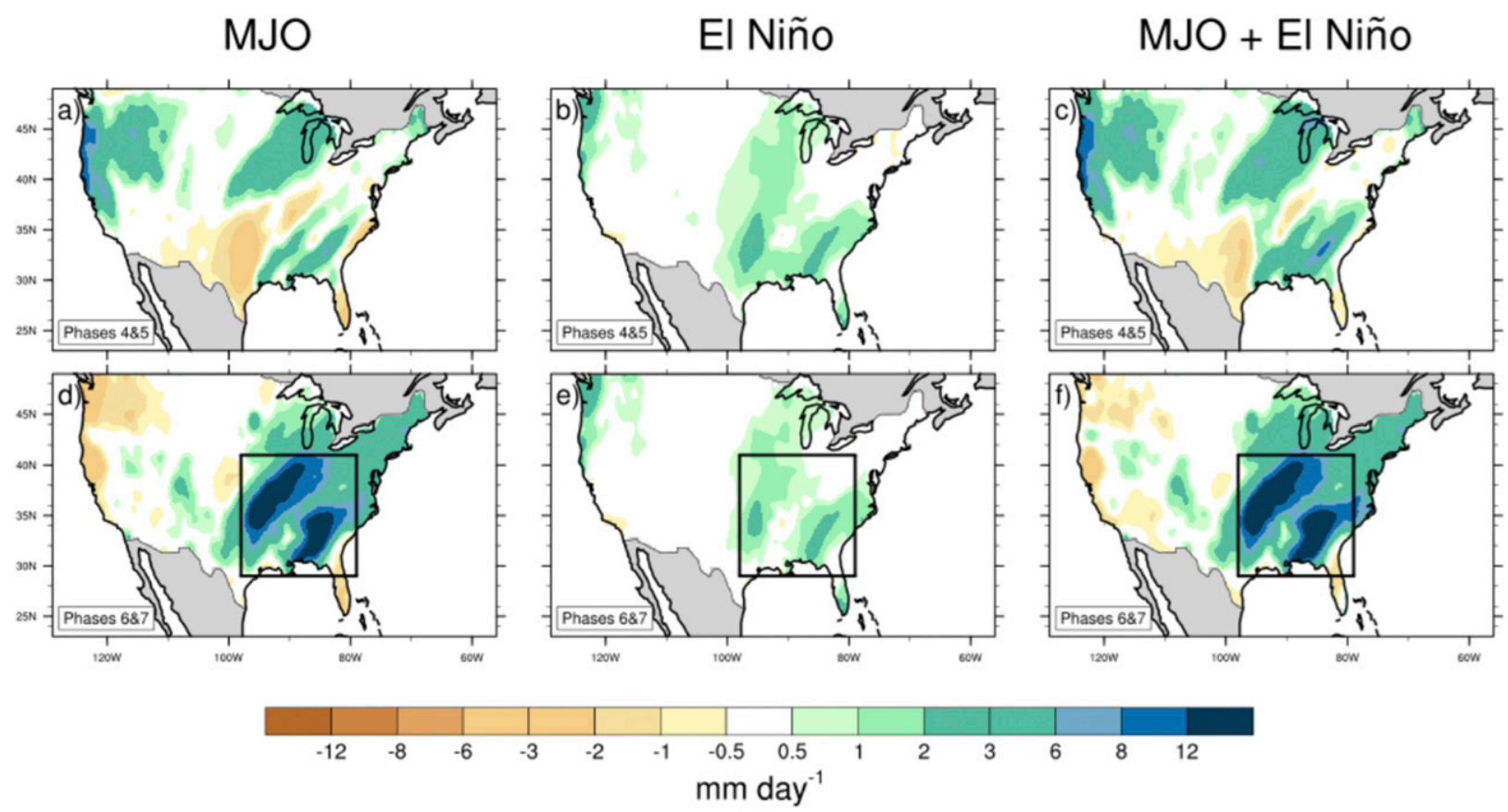

FIG. 15. As in Fig. 8, but for a case study for December 2015 when massive flooding occurred in the central and Southeast United States. There are 9 days each in (a)-(c) phases $4 \& 5$ and (d)-(f) phases $6 \& 7$. The black boxes in phases $6-7$ outline $29^{\circ}-41^{\circ} \mathrm{N}, 101^{\circ}-82^{\circ} \mathrm{W}$.

positive moisture transport advecting warm moist air from the tropics, and anomalous moisture flux convergence results in a positive precipitation anomaly. Conversely, an anticyclonic anomaly, deceleration of the jet and upper-level convergence, advection of cool, dry air from the poles, and anomalous moisture flux divergence results in a negative precipitation anomaly. Thus, tropical MJO forcing drives extratropical geopotential height anomalies and associated lower-tropospheric moisture transport anomalies that explain the patterns of anomalous rainfall.

\section{b. ENSO interference}

The interannual signal is effectively captured by a centered 120-day running mean and is subtracted from the total signal to isolate the subseasonal signal. The interannual signal, which is dominated by ENSO, is broken down in MJO phases to analyze interference with the subseasonal signal, which is dominated by the MJO. These two signals are not necessarily linearly independent, as the low frequency variability modulates the background state and consequently the MJO intensification and propagation as well as it extratropical response. The interannual ENSO signal can constructively or destructively interfere with the modulated MJO teleconnections in the United States. This interference varies in space and time and on a case-bycase basis.
During the 1997/98 El Niño event, the Gulf states during phases $6 \& 7$ showed a substantial increase in precipitation due to constructive interference between the MJO and ENSO signals and significantly increased the explained rainfall variance in that region from $18 \%$ to $29 \%$. In other cases, such as the Gulf states during the 1998-2001 La Niña event, the MJO-modulated signal overwhelmed the expected interannual ENSO signal through destructive interference. However, the relationship between the MJO and El Niño variability is stronger than the MJO-La Niña variability as seen by the magnitudes of the explained variance in Tables 1 and 2. There is constructive interference in the Gulf states during El Niño events, particularly in phases $2 \& 3$ and $6 \& 7$, and destructive interference in the region in phases $4 \& 5$. For La Niña events, there is generally constructive interference in the Gulf states in phases $4 \& 5$, and $6 \& 7$, but destructive interference in phases $8 \& 1$ and $2 \& 3$ (except for Florida). In a time-averaged sense over the entire 39-yr analysis period, the explained variance of winter (November-April) rainfall associated with the MJO in a given phase is quite small $(<5 \%)$. Thus, it is necessary for extreme ENSO events to be analyzed individually for a more comprehensive view of the spatial pattern of the interference.

These findings have significant implications for the United States. For example, the El Niño event of 2015/ 16 was significantly drier in California than predicted, 
resulting in extended droughts. Our results show that the MJO played an important role by producing anomalous dryness in the region. Additionally, the ENSO signal did not contribute the expected positive rainfall signal in California, as in prior strong El Niño events. The result was an anomalously dry winter in California which had anticipated heavy rains.

Furthermore, constructive interference in the central and southeastern United States in December 2015 caused massive flooding and extreme events. The U.S. Geological Survey (https://www.usgs.gov/) reported record breaking flooding across the Midwest United States, exceeding the 1993 and 2011 floods in some of the locations. With an active MJO and a positive ENSO phase occurring, the atmospheric conditions were primed to bring massive rainfall to the area. These tropical influences, combined with local atmospheric patterns, resulted in an extreme precipitation event over a large portion of the central United States. These teleconnection responses are distinct from higherfrequency weather influences, and the influences of both the particular ENSO and MJO phases acted to contribute to this extreme precipitation event. According to NOAA's National Center for Environmental Information (https://www.ncdc.noaa.gov/sotc/national/201513), December 2015 was the only month in their 121 -yr period of record with both the title of warmest and wettest month. Furthermore, the severe precipitation events caused record flooding, severe weather, and heavy snowfall resulting in over 50 fatalities, the deadliest weather event of 2015.

The global teleconnections attributed to ENSO are regularly forecasted. The results from this study show that when the MJO is active and in a particular phase, the extratropical response from the MJO can considerably enhance or mask the interannual ENSO signal in the United States, highlighting the importance of understanding the dynamics and mechanisms of the MJO teleconnections for subseasonal prediction.

\section{c. Discussion}

There are a few caveats to this research worth noting. This work provides an analysis of the teleconnection response in the United States from an MJO forcing that is dependent on the background state modified by the ENSO phases. Separating the linear and nonlinear influences present a challenge since the interaction between the MJO and ENSO is at least partly nonlinear, although it does not imply that the remote responses are nonlinear. Moreover, it is not fully known if linear or nonlinear dynamics dominate teleconnections and signal interference. While this investigation is beyond the scope of this study, applying more sophisticated techniques for separating the linear and nonlinear components of the
MJO and ENSO signals could potentially result in modified teleconnection responses in both magnitude and spatial variability. Modeling of the MJO in both simple linear models and complex global circulation models can offer more detailed insight into the mechanism of the teleconnection. This study analyzes the remote responses between the MJO and ENSO, depending on the state or phase of each phenomenon. It is beyond the scope of this study, but a better understanding of the nonlinear interactions between the two can provide more confidence in predictability, especially during extreme ENSO events. The case studies of California during the winter 2015/16 El Niño and the central/Southeast United States during December 2015 highlight the substantial impact of destructive and constructive interference of the MJO and ENSO signals can have on socioeconomic systems.

This work can help to advance subseasonal to seasonal predictability and expand our knowledge of subseasonal phenomena. Understanding the remote responses from both the MJO and ENSO has the potential to increase confidence in subseasonal and seasonal forecasts if one can predict the subseasonal variations during a particular ENSO phase.

Acknowledgments. The authors thank Dr. Jim Benedict who provided valuable suggestions and insight for this work, and two anonymous reviewers whose suggestions improved this study greatly. This work was supported through NOAA Grants NA15OAR4320064, NA16OAR4310141, and N16OAR4310149 and DOE Grant DE-SC0019433.

\section{REFERENCES}

Becker, E. J., E. H. Berbery, and R. W. Higgins, 2011: Modulation of cold-season U.S. daily precipitation by the Madden-Julian oscillation. J. Climate, 24, 5157-5166, https://doi.org/10.1175/ 2011JCLI4018.1.

Diaz, H. F., M. P. Hoerling, and J. K. Eischeid, 2001: ENSO variability, teleconnections and climate change. Int. J. Climatol., 21, 1845-1862, https://doi.org/10.1002/joc.631.

Higgins, R. W., and K. C. Mo, 1997: Persistent North Pacific circulation anomalies and the tropical intraseasonal oscillation. J. Climate, 10, 223-244, https://doi.org/10.1175/15200442(1997)010<0223:PNPCAA > 2.0.CO;2.

Hoell, A., M. Barlow, M. C. Wheeler, and C. Funk, 2014: Disruptions of El Niño-Southern Oscillation teleconnections by the Madden-Julian oscillation. Geophys. Res. Lett., 41, 998-1004, https://doi.org/10.1002/2013GL058648.

Hoerling, M. P., and A. Kumar, 1997: Why do North American climate anomalies differ from one El Niño event to another? Geophys. Res. Lett., 24, 1059-1062, https://doi.org/10.1029/ 97GL00918.

Hoskins, B. J., and D. J. Karoly, 1981: The steady linear response of a spherical atmosphere to thermal and orographic forcing. J. Atmos. Sci., 38, 1179-1196, https://doi.org/10.1175/15200469(1981)038<1179:TSLROA > 2.0.CO;2.

Jiang, X., 2017: Key processes for the eastward propagation of the Madden-Julian oscillation based on multimodel simulations. 
J. Geophys. Res. Atmos., 122, 755-770, https://doi.org/10.1002/ 2016JD025955.

_, M. Zhao, E. D. Maloney, and D. E. Waliser, 2016: Convective moisture adjustment time scale as a key factor in regulating model amplitude of the Madden-Julian oscillation. Geophys. Res. Lett., 43, 10 412-10 419, https://doi.org/10.1002/2016GL070898.

Johnson, N. C., D. C. Collins, S. B. Feldstein, M. L. L'Heureux, and E. E. Riddle, 2014: Skillful wintertime North American temperature forecasts out to 4 weeks based on the state of ENSO and the MJO. Wea. Forecasting, 29, 23-38, https://doi.org/ 10.1175/WAF-D-13-00102.1.

Jones, C., and L. M. Carvalho, 2012: Spatial-intensity variations in extreme precipitation in the contiguous United States and the Madden-Julian oscillation. J. Climate, 25, 4898-4913, https:// doi.org/10.1175/JCLI-D-11-00278.1.

Kalnay, E., and Coauthors, 1996: The NCEP/NCAR 40-Year Reanalysis Project. Bull. Amer. Meteor. Soc., 77, 437-471, https:// doi.org/10.1175/1520-0477(1996)077<0437:TNYRP>2.0.CO;2.

Kumar, A., and M. P. Hoerling, 1997: Interpretation and implications of the observed inter-El Niño variability. J. Climate, 10, 83-91, https://doi.org/10.1175/1520-0442(1997)010<0083: IAIOTO $>2.0 . \mathrm{CO} ; 2$.

Lau, W. K. M., and D. E. Waliser, 2011: Intraseasonal Variability in the Atmosphere-Ocean Climate System. Springer Science and Business Media, 613 pp.

Lin, H., and G. Brunet, 2011: Impact of the North Atlantic Oscillation on the forecast skill of the Madden-Julian oscillation. Geophys. Res. Lett., 38, L02802, https://doi.org/10.1029/ 2010GL046131.

- _ - , and J. Derome, 2008: Forecast skill of the MaddenJulian oscillation in two Canadian atmospheric models. Mon. Wea. Rev., 136, 4130-4149, https://doi.org/10.1175/2008MWR2459.1.

Madden, R. A., and P. R. Julian, 1971: Detection of a 4050 day oscillation in the zonal wind in the tropical Pacific. J. Atmos. Sci., 28, 702-708, https://doi.org/10.1175/15200469(1971)028<0702:DOADOI > 2.0.CO;2.

— and - 1972: Description of global-scale circulation cells in the tropics with a 40-50 day period. J. Atmos. Sci., 29, 1109-1123, https:// doi.org/10.1175/1520-0469(1972)029<1109:DOGSCC >2.0.CO;2.

Moon, J. Y., B. Wang, and K. J. Ha, 2011: ENSO regulation of MJO teleconnection. Climate Dyn., 37, 1133-1149, https:// doi.org/10.1007/s00382-010-0902-3.

Paek, H., J.-Y. Yu, and C. Qian, 2017: Why were the 2015/2016 and 1997/1998 extreme El Niños different? Geophys. Res. Lett., 44, 1848-1856, https://doi.org/10.1002/2016GL071515.

Pegion, K., and Coauthors, 2019: The Subseasonal Experiment (SubX): A multimodel subseasonal prediction experiment. Bull. Amer. Meteor. Soc., 100, 2043-2060, https://doi.org/ 10.1175/BAMS-D-18-0270.1.

Pohl, B., and A. J. Matthews, 2007: Observed changes in the lifetime and amplitude of the Madden-Julian oscillation associated with interannual ENSO sea surface temperature anomalies. J. Climate, 20, 2659-2674, https://doi.org/10.1175/ JCLI4230.1.

Riddle, E. E., M. B. Stoner, N. C. Johnson, M. L. L'Heureux, D. C. Collins, and S. B. Feldstein, 2013: The impact of the MJO on clusters of wintertime circulation anomalies over the North American region. Climate Dyn., 40, 1749-1766, https://doi.org/ 10.1007/s00382-012-1493-y.

Roundy, P. E., K. MacRitchie, J. Asuma, and T. Melino, 2010: Modulation of the global atmospheric circulation by combined activity in the Madden-Julian oscillation and the El NiñoSouthern Oscillation during boreal winter. J. Climate, 23, 4045-4059, https://doi.org/10.1175/2010JCLI3446.1.

Sardeshmukh, P. D., and B. J. Hoskins, 1988: The generation of global rotational flow by steady idealized tropical divergence. J. Atmos. Sci., 45, 1228-1251, https://doi.org/10.1175/15200469(1988)045<1228:TGOGRF>2.0.CO;2.

Siler, N., Y. Kosaka, S.-P. Xie, and X. Li, 2017: Tropical ocean contributions to California's surprisingly dry El Niño of 2015/ 16. J. Climate, 30, 10 067-10 079, https://doi.org/10.1175/JCLID-17-0177.1.

Stan, C., D. M. Straus, J. S. Frederiksen, H. Lin, E. D. Maloney, and C. Schumacher, 2017: Review of tropical-extratropical teleconnections on intraseasonal time scales. Rev. Geophys., $\mathbf{5 5}$, 902-937, https://doi.org/10.1002/2016RG000538.

Vitart, F., and Coauthors, 2017: The Subseasonal to Seasonal (S2S) prediction project database. Bull. Amer. Meteor. Soc., 98, 163173, https://doi.org/10.1175/BAMS-D-16-0017.1.

Wang, T., S. Wong, and E. J. Fetzer, 2015: Cloud regime evolution in the Indian monsoon intraseasonal oscillation: Connection to large-scale dynamical conditions and the atmospheric water budget. Geophys. Res. Lett., 42, 9465-9472, https://doi.org/ 10.1002/2015GL066353.

Wheeler, M. C., and H. H. Hendon, 2004: An all-season real-time multivariate MJO index: Development of an index for monitoring and prediction. Mon. Wea. Rev., 132, 1917-1932, https://doi.org/10.1175/1520-0493(2004)132<1917:AARMMI> 2.0.CO;2.

Xie, P., A. Yatagai, M. Chen, T. Hayasaka, Y. Fukushima, C. Liu, and S. Yang, 2007: A gauge-based analysis of daily precipitation over East Asia. J. Hydrometeor., 8, 607-626, https:// doi.org/10.1175/JHM583.1.

Yang, X. S., L. W. Jia, S. B. Kapnick, T. L. Delworth, G. A. Vecchi, R. Gudgel, S. Underwood, and F. R. Zeng, 2018: On the seasonal prediction of the western United States El Niño precipitation pattern during the 2015/16 winter. Climate Dyn., 51, 3765-3783, https://doi.org/10.1007/s00382-018-4109-3.

Zhang, C., 2005: Madden-Julian oscillation. Rev. Geophys., 43, RG2003, https://doi.org/10.1029/2004RG000158.

Zhu, H., and H. H. Hendon, 2015: Role of large-scale moisture advection for simulation of the MJO with increased entrainment. Quart. J. Roy. Meteor. Soc., 141, 2127-2136, https:// doi.org/10.1002/qj.2510. 